Trinity University

Digital Commons @ Trinity

Geosciences Student Honors Theses

Geosciences Department

$5-2019$

\title{
Geomechanical Analysis of Sedimentary Layering as a Structural Control on Fault Propagation
}

Curtis K. Segarra

Trinity University, cksegarra@gmail.com

Follow this and additional works at: https://digitalcommons.trinity.edu/geo_honors

\section{Recommended Citation}

Segarra, Curtis K., "Geomechanical Analysis of Sedimentary Layering as a Structural Control on Fault Propagation" (2019). Geosciences Student Honors Theses. 19.

https://digitalcommons.trinity.edu/geo_honors/19

This Thesis open access is brought to you for free and open access by the Geosciences Department at Digital Commons @ Trinity. It has been accepted for inclusion in Geosciences Student Honors Theses by an authorized administrator of Digital Commons @ Trinity. For more information, please contact jcostanz@trinity.edu. 


\section{Geomechanical Analysis of Sedimentary Layering as a Structural Control on Fault Propagation}

\section{Curtis Segarra}

A departmental senior thesis submitted to the Department of Geosciences at Trinity University in partial fulfillment of the requirements for graduation with departmental honors.

$4 / 22 / 2019$

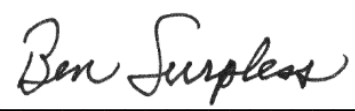

Dr. Benjamin Surpless, Thesis Advisor Dr. Kathleen Surpless, Department Chair

Michael Soto, AVPAA 


\section{Student Agreement}

I grant Trinity University (“Institution"), my academic department ("Department"), and the Texas Digital Library ("TDL") the non-exclusive rights to copy, display, perform, distribute and publish the content I submit to this repository (hereafter called "Work") and to make the Work available in any format in perpetuity as part of a TDL, Digital Preservation Network ("DPN"), Institution or Department repository communication or distribution effort.

I understand that once the Work is submitted, a bibliographic citation to the Work can remain visible in perpetuity, even if the Work is updated or removed.

I understand that the Work's copyright owner(s) will continue to own copyright outside these non-exclusive granted rights.

I warrant that:

1) I am the copyright owner of the Work, or

2) I am one of the copyright owners and have permission from the other owners to submit the Work, or

3) My Institution or Department is the copyright owner and I have permission to submit the Work, or

4) Another party is the copyright owner and I have permission to submit the Work.

Based on this, I further warrant to my knowledge:

1) The Work does not infringe any copyright, patent, or trade secrets of any third party,

2) The Work does not contain any libelous matter, nor invade the privacy of any person or third party, and

3) That no right in the Work has been sold, mortgaged, or otherwise disposed of, and is free from all claims.

I agree to hold TDL, DPN, Institution, Department, and their agents harmless for any liability arising from any breach of the above warranties or any claim of intellectual property infringement arising from the exercise of these non-exclusive granted rights."

\section{I choose the following option for sharing my thesis (required):}

[ $\mathbf{X}$ ] Open Access (full-text discoverable via search engines)

[ ] Restricted to campus viewing only (allow access only on the Trinity University campus via digitalcommons.trinity.edu)

I choose to append the following Creative Commons license (optional): 


\section{ACKNOWLEDGEMENTS}

This material is based upon work supported by the Keck Geology Consortium and the National Science Foundation under Grant No. 1659322. I could not have done this work without the support from my thesis adviser Dr. Benjamin Surpless, Dr. Kevin Smart, my reader Dr. Glenn Kroeger, and everyone involved in the Keck Geology Consortium. Although I present original work within this thesis, each sentence stems from countless hours of discussion with the aforementioned people. As such, I consider this a group effort and I feel lucky to have been able to work alongside such amazing minds.

From my initial outings with Dr. Surpless and the other Keck participants, to thorough discussions about the finer points of geomechanical modeling with Dr. Smart, all the way through the final reading by Dr. Kroeger, this project has taught me countless skills that have not only resulted in the production of this work, but have set me on a path towards never-ending scientific inquiry. Thank you to everyone who made this possible. 


\section{ABSTRACT}

Deformation associated with normal fault propagation and displacement places controls on the distribution and flow of sub-surface fluids. With a better understanding of how sedimentary units deform in response to a propagating fault, I can better predict how fluids might flow through the system at initial stages of displacement. To elucidate the role of sedimentary layering on fault tip propagation, I use ABAQUS/Standard to conduct a finite element analysis of a propagating normal fault to identify patterns of stress distribution and accumulation. While holding material properties constant (e.g., Young's Modulus, Poisson's Ratio, dilation angle, and the internal angle of friction), I simulate the initial stages of plastic failure in front of a normal fault tip propagating at $60^{\circ}$ through bedded sandstone at low levels ( $<0.09 \mathrm{~m}$ displacement). I test the effects of incrementally increasing the number of mechanical layers from a single 20-m thick layer to five 4-m thick layers.

I find that the presence of layering allows for simultaneous, but discontinuous, plastic failure in multiple locations ahead of a propagating fault tip. Additionally, although inter-layer stress accumulation is hindered by an increased number of layers, elevated regions of maximum stress occur further ahead of the propagating fault tip with an increased number of layers. Additionally, I show that the coefficient of friction between beds controls the angle at which offfault-plane stress develops.

My results show that mechanical layering systematically re-distributes stress ahead of a propagating fault tip so that a section of sandstone with multiple layers will fracture differently than a single massive bed. This predictable mechanical behavior is likely to influence the development of fluid conduits associated with fracturing during the early stages of normal fault propagation, a finding that has implications for the evolution of permeability structure of realworld fault zones in the subsurface. 


\section{TABLE OF CONTENTS}

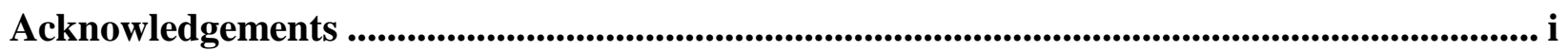

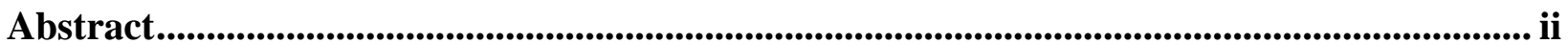

Table of Contents ...................................................................................................................................... iii

List of Figures................................................................................................................................................. iv

List of Tables and Equations ..................................................................................................................................v

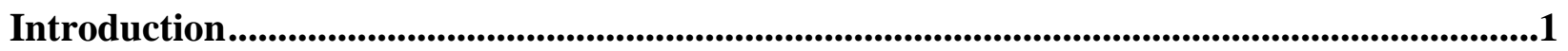

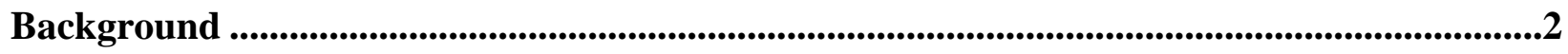

Finite Element Analysis as a Geomechanical Modeling Technique ......................................2

Model Building Theory in Abaqus .......................................................................................4

Methods............................................................................................................................................................

Building a Model of a Normal Fault System .........................................................................

Analysis Procedure ......................................................................................................................11

Data and Results .................................................................................................................................................13

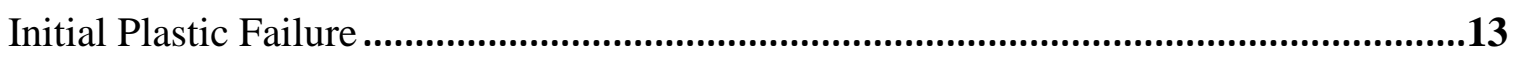

Initial Stress Distribution ...........................................................................................16

Initial Plastic Strain Distribution and Development ...........................................................18

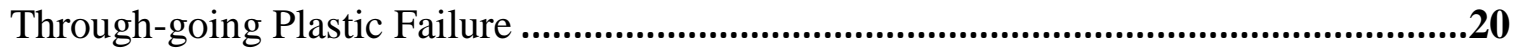

Through-going Stress Distribution .....................................................................................20

Limitations of Normal Fault Propagation Model Results.....................................................23

Geometric Limitations ...................................................................................................23

Resolution of Results ...................................................................................................24

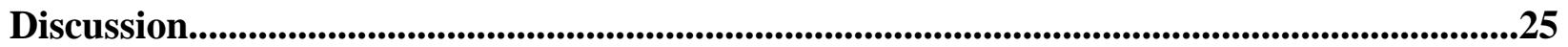

Field and Subsurface Exploration Applications ..................................................................26

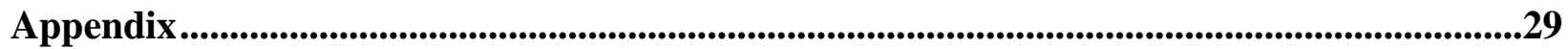

References................................................................................................................................................37 


\section{LIST OF FIGURES}

Figure 1. Example of Model Geometry Showing Three Test Beds.....................................................9

Figure 2. Exploded View of Model Showing Contact Definitions.........................................................9

Figure 3. Amount of Displacement Necessary to Cause Plastic Failure in Each Model................14

Figure 4. Initial Plastic Failure and Stress Gradients at Low Displacement.....................................15

Figure 5. Comparison of Max. In-plane Principal Stress Distributions in Three Beds ..................16

Figure 6. Maximum In-plane Principal Logarithmic Strain Distribution at Low Displacement..18

Figure 7. Plastic Failure and Stress Gradients at Increased Levels of Displacement .....................21

Figure 8. Off-fault-plane Max. In-plane Principal Stress Concentrations ........................................22

Figure A1. Initial Plastic Failure and Stress Gradients at Low Displacement $(1 \& 2$ beds)..........29

Figure A2. Initial Plastic Failure and Stress Gradients at Low Displacement (3 beds)..................30

Figure A3. Initial Plastic Failure and Stress Gradients at Low Displacement (4 beds)..................31

Figure A4. Initial Plastic Failure and Stress Gradients at Low Displacement ( 5 beds)...................32

Figure A5. Comparison of Max. In-plane Principal Stress Distributions in 1 \& 2 Beds.................33

Figure A6. Comparison of Max. In-plane Principal Stress Distributions in 3 Beds.........................34

Figure A7. Comparison of Max. In-plane Principal Stress Distributions in 4 Beds.......................35

Figure A8. Comparison of Max. In-plane Principal Stress Distributions in 5 Beds.......................36 


\section{LIST OF EQUATIONS AND TABLES}

Equation 1. Symbolizing Finite Element Matrices..................................................................3

Equation 2. Hooke's Law for Modeling the Elastic Properties of Rock ........................................5

Equation 3. Mohr-Coulomb Criterion for Modeling Plasticity ...........................................................5

Equation 4. Coulomb Model for Sliding Contact Behavior .................................................................6

Table 1. Geomechanical Model Material Properties...........................................................................10

Table 2. Areas of Elevated Tensile Stress under low Displacement and Constant Friction ..........17

Table 3. Maximum Stress and Strain Achieved in Each Model .....................................................19 


\section{INTRODUCTION}

Normal faults, and the deformation associated with their propagation, are important structural controls on the flow of subsurface fluids and the propagation of slip during an earthquake, so understanding initial controls on fault tip propagation through bedded sedimentary strata may aid resource exploration and the mitigation of seismic hazard. Though previous researchers have acknowledged the effects of sedimentary layering as barriers to fault propagation (e.g. Cooke and Pollard, 1997; Cooke et al., 2001; Peacock, 2002; Hayano and Ishii, 2016), previous research has failed to produce a systematic analysis on the role of mechanical layering on fault tip propagation. Therefore, building upon previous geomechanical modeling techniques (Smart et al., 2004, 2009, 2010b, 2010a, 2012; Doff, 2015; Sattari and Eaton, 2015), I develop an experimental finite element model that permits me to analyze the influence of stratigraphic discontinuities upon stress and strain ahead of a propagating fault tip. I use this model to address two primary research goals: 1 . To systematically analyze the influence of planar bedding upon stress and strain fields ahead of a propagating normal fault and; 2 . To develop a predictive model of fracture distribution during the propagation of a normal fault through well-bedded stratigraphy.

In order to conduct an empirical analysis, I use ABAQUS/Standard finite element modeling software (Dassault Systèmes, 2018) to create a 2D model that permits me to systematically assess the role of bedding upon stress and strain distribution during normal fault propagation. I use this approach to control a large number of important physical variables (such as bedding thickness, fault displacement, physical properties of the strata, and friction between beds), and the software permits me to efficiently test different factors (e.g. the coefficient of friction between beds) across a range of values. Because this model simulates propagation of a 
fault through bedded sandstone, these results can be applied by other scientists to similar geologic settings.

\section{BACKGROUND}

\section{Finite Element Analysis as a Geomechanical Modeling Technique}

Geomechanical modeling is a method for simplifying physical geologic processes into replicable, testable models; geomechanical modeling permits me to conduct an analysis of stress and strain while maintaining control of the geometry and kinematics of the model pieces. Smart et al (2012) note that there are multiple methods of numerical geomechanical analysis, including finite element, boundary element, and discrete element analysis — each of which rely on predefined physical material properties as inputs and are thus potentially useful for an empirical study of fault propagation through strata defined by physical properties. Yet only finite element analysis can model the spatial distribution of stress and strain throughout each layer in a manner that allows prediction of fracture formation in elastic-plastic materials while remaining computationally efficient (Smart et al., 2012).

I use finite element analysis (FEA), a method for calculating specific output quantities, (i.e. stress and strain fields) as a solution to a given mathematical problem, within a multi-piece model (Cook, 1995). By dividing my model into "elements", across which displacement, stress, and strain can be interpolated, I can analyze the spatial distribution of stress and strain (Cook, 1995). Mathematically, FEA is a means of interpolation of the output quantity through piecewise polynomial calculations, whereby a quantity, such as displacement, stress, or strain can be interpolated across the surface of the element (Cook, 1995). The interpolation calculation uses the values expressed at the element corners, commonly called "nodes" (Cook, 1995). This process may be iterated over a finite number of nodes in order to solve for a field quantity (such 
as displacement) over a large, multi-piece system (Smart, 2019). Because this process requires simultaneously solving a large number of algebraic equilibrium equations, a computer is required (Cook, 1995).

When applied to stress analysis, FEA uses a matrix of equations, which may be symbolized as:

$$
\mathrm{KD}=\mathrm{R} \text {. }
$$

Cook (1995, p. 1), where K is the "stiffness matrix" [a vector of known constants], D is a vector of unknowns, and $\mathrm{R}$ is a vector of known or applied loads. Because loads are supplied within their own matrix, FEA is versatile, and can be used for nearly any load over any finite area (Cook, 1995). The stiffness matrix $(\mathrm{K})$ is a summation of the stiffness of each individual element within the model, where each individual element's stiffness is a function of the size and shape of the element, the elastic properties, and the displacement occurring on the individual element (e.g., Dietrich and Decker, 1975). Using this formulation, ABAQUS/Standard can solve for the vector of unknowns (D) and provide a stress and strain analysis for each element in a model.

Previous researchers modeling of faulting and folding mechanisms have used Dassault Systèmes' ABAQUS software (e.g. Smart et al., 2012; Doff, 2015; Sattari and Eaton, 2015), which is appropriate for geomechanical modeling on various scales in both 2D and 3D (Smart et al., 2004, 2009, 2010a, 2010b, 2012). Furthermore, ABAQUS includes Lagrangian mechanics (i.e., it can model output variables in any specified location throughout the model) and the ability to handle non-linear mathematical modeling, it is well suited to model high strain values as well as large displacements along frictional contacts (Smart et al., 2012). Thus, ABAQUS provides suitable capabilities for modeling fault movement and incurred strains on frictionally-interfaced strata. ABAQUS also contains both preset and adjustable inputs, such as Mohr-Coulomb 
plasticity and frictional sliding contacts, that are suitable for modeling rock materials as well as fault contacts (Smart et al., 2012). Therefore, I can use ABAQUS to perform static stress analysis on a diverse range of fault movement scenarios.

\section{Model Building Theory in ABAQUS}

\section{D Modeling}

For the purpose of modeling fault tip propagation within layered strata, the simplifications provided by a $2 \mathrm{D}$ model allow efficient computation and effective stress and strain analysis. Smart et al. (2012) used a 2D model to examine yield stress on elastic-plastic layers, and Melosh and Williams (1989) used 2D finite element analysis to assess stress near a normal fault. Thus, 2D analyses are can be used to study stress and strain fields within a geomechanical model.

\section{Meshing and Element Assignment}

The shape and number of elements that compose a model directly influence the way the model is able to deform. Therefore, the element type used within a model must allow appropriate distortion while remaining computationally efficient. Moreover, the choice of how many elements to use in order to describe a system is a potential source of model error (Cook, 1995); if a model piece expected to undergo stress or strain displacements is composed of too few

elements (i.e., is coarsely meshed), regardless of element type, results are likely to be inaccurate (Dassault Systèmes, 2008). Element choice errors and meshing errors can be correspondingly minimized by choosing appropriate elements and providing a sufficiently dense mesh.

\section{Material Properties}

The results of a finite element analysis strongly depend upon material properties specified within a model (Smart et al. 2012). Smart et al. (2012) note that within geomechanical finite 
element models, for an analysis of permanent deformation, elastic-plastic material descriptions are preferable to other material definitions, since permanent deformation may be captured with elastic-plastic behavior. Although a simple approach, I use a Mohr-Coulomb elastic-plastic material model to generalize rocks within the upper crust (e.g., Ord, 1991; Vermeer and DeBorst, 1984; Zienkiewicz and Mroz, 1984; Jaeger and Cook, 1979; Rudnicki and Rice, 1975; Smart et al., 2010a). Following the material definitions used by Smart et al. (2010a) for an analysis in ABAQUS software, Hooke's law characterizes the elastic properties of the rock such that:

$$
\sigma=E \varepsilon
$$

in which stress $(\sigma)$ is a tensor, strain $(\varepsilon)$ is a tensor, and $E$ is a matrix describing the stiffness of a material. The plastic component, then, follows the Mohr-Coulomb criterion such that:

$$
\tau=c+\sigma \tan \phi
$$

where $\tau$ is the shear stress, $\sigma$ is the normal stress, $\phi$ is the angle of internal friction, and cohesion is defined as $c$ (e.g. Smart et al., 2010a). Smart et al., (2010a) in their model, incorporate Menétrey and William's (1995) formulation that allows for plastic flow under loads greater than the Mohr-Coulomb criterion; this is achieved by including a dilation angle $(\psi)$ into the material model, which allows for disassociation when $\phi \neq \psi$ (Smart et al., 2010a); Smart et al., (2012) simply define the dilation angle as half of the internal angle of friction, though dilation angle for generalized sandstone may be estimated at 10\% the internal angle of friction (Smart, 2018). 


\section{Contact Properties}

ABAQUS/Standard allows the user to define contact properties within the model. Smart et al. (2010a) employ a Coulomb model to define sliding behavior:

$$
\tau_{\text {crit }}=\mu \sigma
$$

such that initial slip along the contact occurs when shear stress exceeds a critical value $\left(\tau_{\text {crit }}\right)$ as defined by the coefficient of friction $(\mu)$ and the stress normal to the contact plane $(\sigma)$ in Abaqus (e.g. Smart et al., 2010a).

\section{Boundary Conditions and Applied Forces}

Because the virtual model space provided by ABAQUS implies no inherent conditions, all boundary conditions used within a modeled system must be described. In addition to restricting movement of various model pieces, forces/loads applied to model pieces must also be prescribed. Ultimately, these loads and boundary conditions are the primary input ABAQUS/Standard uses to solve for output. Thus, proper constraints on a model (boundary conditions) as well as appropriate forces and loads, are essential for an efficient, effective analysis. Still, over-constraint of elements may lead to computational issues as well (Smart, 2018). Thus, trial-and-error techniques must be employed in order to select boundary conditions.

\section{Using ABAQUS Output to Predict Plastic Failure}

Inherent in the mathematics of finite element analysis is an issue with modeling discontinuities; because finite element analysis is based upon the assumption that the elements that make up a model are linked at nodes, it is computationally problematic to try to force elements apart into a discontinuous mesh. Though it can be done, Moes et al. (1999) note that, in order to model discontinuities, the mesh of a model must be adaptive (changing) throughout the modeling steps; such an adaptive system would drastically increase computational requirements 
and is not well-supported by ABAQUS. However, Bourne et al. (2000) point out that an examination of the pre-plastic failure stress field can act as a proxy for predicting discontinuous behavior. As such, the limitation of modeling discontinuities can be overcome by assuming that the elements which yield under their specified failure criterion would become discontinuous if modeling behavior permitted.

Following that line of logic, an analysis of stress and strain vectors as output variables is sufficient for modeling simple fault propagation (e.g., Smart et al., 2012). In particular, analyzing the directional component of maximum principal stress and strain allows for a reasonable spatial prediction of fracture formation. Additionally, a flag (Boolean output value), indicating that plastic failure has occurred, is available for elastic-plastic elements. This output, combined with an examination of maximum displacement, is a quick method to identify localized fracture formation within a model.

\section{METHODS}

\section{Building a Model of a Normal Fault System}

\section{Model Geometry}

The model I developed replicates a planar, dip-slip normal fault with a $60^{\circ}$ dip. This geometry represents normal fault systems at depths shallower than about $10 \mathrm{~km}$ (e.g., Jackson and McKenzie, 1983). The model captures the initial stages of propagation of a pre-existing fault into undeformed sandstone beds with thicknesses of several meters; the model is not intended to recreate initial fault formation but rather to show initial stages of propagation through bedding after initial fault formation.

I use a model geometry similar to the geometry used by Smart et al. (2010a). The underlying fault block of the footwall (B1, Fig. 1) imposes displacement on the model. The 
overlying fault block of the footwall (B3, Fig. 1), provides an overburden load and is not restrained. Pinned fault blocks in the hanging wall (B2 and B3, Fig. 1) cannot move horizontally nor vertically, ensuring displacement occurs along the fault plane. Figure 1 includes the stress tensor I use to describe a pre-existing stress field within the test strata (ABAQUS uses engineering sign conventions for stress, so that positive stress is tensile and negative stress is compressive); this pre-described stress field applied to the elements within the test strata is paired with inward pressure applied to the top and sides of the model (Fig. 1). Describing preexisting stresses using both pre-defined stresses applied to the elements as well as pressure applied to the boundary helps ensure computational efficiency and simulates stresses due to a slight overburden (Smart, 2018). This pre-defined overburden represents near-surface conditions.

The overlying fault blocks (B3 and B4 in figure 1) are pre-faulted, which prevents the overlying strata from interfering with the model. If the overlying blocks were modeled as a single rectangular block (i.e., had no pre-defined fault surface) the deformation of the overlying block would affect the deformation of the underlying test beds, but since my analysis is intended to examine stress and strain imparted by the propagating fault (between B1 and B2), I pre-fault the B3 and B4 to minimize the influence of these overlying blocks. The 20 meters of test strata, sandwiched between the fault blocks, is allowed to deform (Fig. 1). I vary the number of beds throughout the analysis, while keeping the entire test section 20 meters thick. The test beds are initially homogeneous, with no pre-existing deformation or preferred planes of weakness. This ensures that my results show only the effect of bedding planes on the early stages of stress and strain development throughout the strata. 


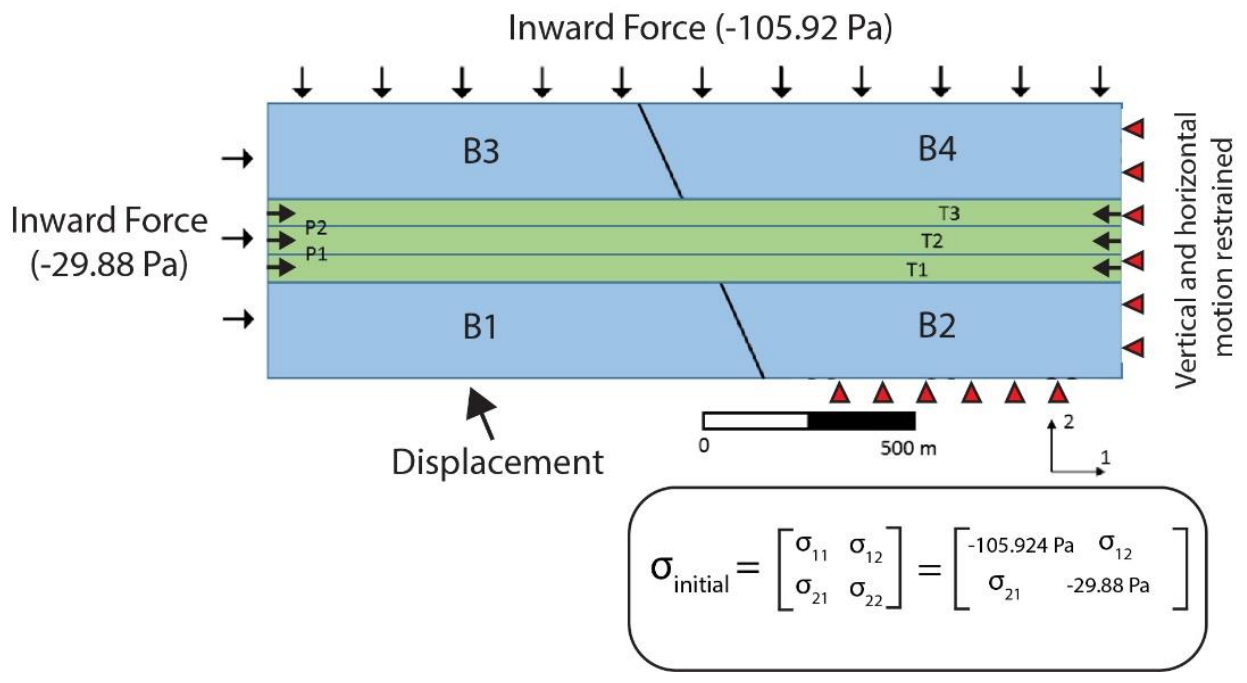

Figure 1. Example of model geometry showing three test beds (T1-T3). The stress tensor indicates the pre-defined stress state within the test beds. Displacement (up and to the left) simulates propagation of a normal fault with $60^{\circ}$ dip. Note that the scale in the 2-direction has been exaggerated for illustration (total vertical thickness of the test strata is $20 \mathrm{~m}$; the fault plane is kept at a $60^{\circ}$ dip for illustration).

Within my model, I define the fault surface and orientation as a planar, non-frictional contact. Similarly, I define contacts between the test beds and the fault blocks as planar, nonfrictional contacts (green contacts in Fig. 2). I do not analyze the role of these outer contacts. The contacts between test strata (red contacts in Fig. 2) are frictional, planar contacts; I vary the coefficient of friction between test beds from $0.15 \mu$ to $0.9 \mu$.

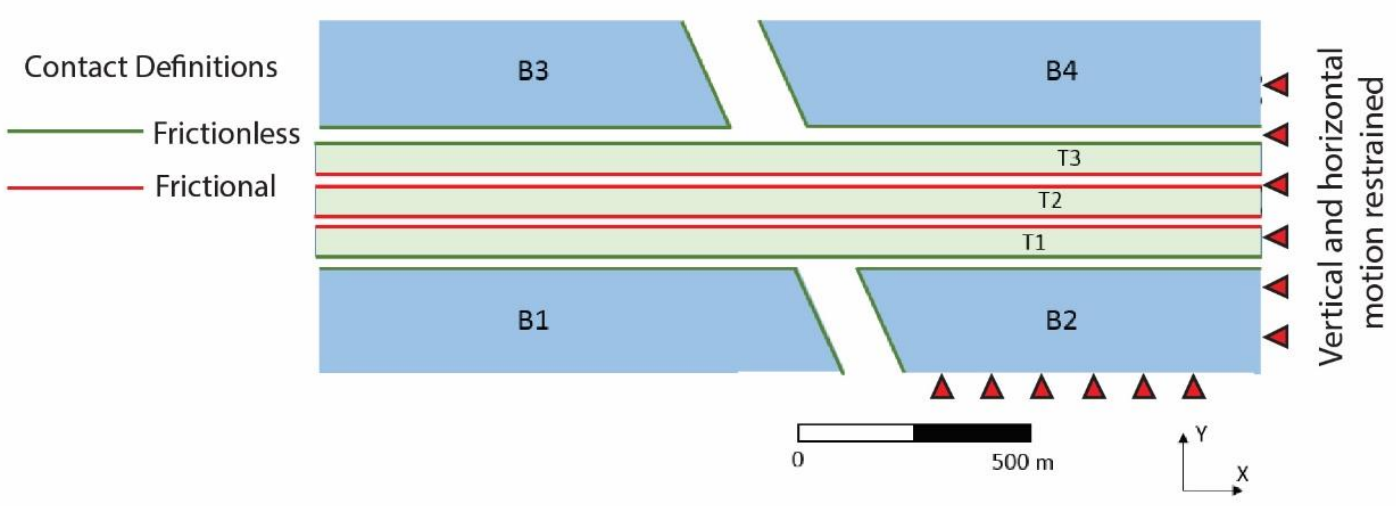

Figure 2. Blown-apart example of model with three test beds (T1-T3) showing contact definitions. Contacts between beds (red lines) are frictional. Contacts between fault blocks (green lines) are frictionless. Note that the scale in the y-direction is exaggerated; the fault plane is kept at a $60^{\circ}$ dip for illustration. 


\section{Material Properties and Mesh}

Following Smart et al.’s (2010a) modeling protocol, I employ elastic-plastic material behavior for the deformable beds and an elastic material with a high Young's Modulus (30 GPa) for the fault blocks (B1 through B4, Fig. 1); the material properties displayed in Table 1 are held constant for all models.

Table 1. Geomechanical model material properties.

\begin{tabular}{|c|c|c|c|c|c|c|}
\hline $\begin{array}{c}\text { Material } \\
\text { Properties }\end{array}$ & $\begin{array}{c}\text { Density } \\
\left(\mathbf{k g} / \mathbf{m}^{\mathbf{3}}\right)\end{array}$ & $\begin{array}{c}\text { Young's } \\
\text { Modulus } \\
\mathbf{( G P a})\end{array}$ & $\begin{array}{c}\text { Poisson's } \\
\text { Ratio }\end{array}$ & $\begin{array}{c}\text { Friction } \\
\text { Angle }\left(^{\circ}\right)\end{array}$ & $\begin{array}{c}\text { Dilation } \\
\text { Angle }\left(^{\circ}\right)\end{array}$ & $\begin{array}{c}\text { Cohesion } \\
(\mathbf{M P a})\end{array}$ \\
\hline $\begin{array}{c}\text { Test Beds } \\
\text { (sandstone) }\end{array}$ & 2328 & 19.73 & 0.22 & 44 & 4.4 & 21.15 \\
\hline $\begin{array}{c}\text { Fault } \\
\text { Blocks }\end{array}$ & N/A & 30 & 0.5 & N/A & N/A & N/A \\
\hline
\end{tabular}

Following guidelines for stress and strain analysis suggested by the makers of ABAQUS, my model makes use of linear quadrilateral plane strain elements with five points of integration (CPE4R), since ABAQUS provides both stress and strain output for CPE4R elements.

This choice of element type is consistent with the assumption that the displacement step of the analysis may produce bending within the test beds (Dassault Systèmes, 2008). Yet, such an element type is susceptible to "hourglassing", or more-than-reasonable bending, so "hourglass control" is enabled to add rigidity to the elements (Dassault Systèmes, 2008).

The mesh density, as defined by the size of "elements," which each model piece is divided into for mathematical interpolation of stress and strain, controls the permissible deformation of each model piece and the resolution of the results. Because I do not intend to deform the four bounding blocks of the model (B1 through B4), I define a coarse mesh for the four bounding blocks. Mesh resolution of the test beds is fine near the center of the beds and coarse near the edges of the model, ensuring higher-resolution analysis near the propagating fault. The vertical mesh resolution is constant; each element is 1 meter in the vertical dimension. 
Because the four fault blocks surrounding the test beds only deform minimally, the mesh resolution should not affect the results; coarser mesh in the fault blocks aids computational efficiency.

\section{Analysis Procedure}

In the modeling presented here, I perform a three-step analysis. In the initial step, I apply boundary conditions. In the second step, I apply forces to the model, allowing the model to achieve equilibrium and begin displacement. Total displacement is incremented non-uniformly based upon the computational complexity of the model. Finally, once the displacement is complete, I review the results in the output step. I apply this procedure to one 20 -meter-thick bed, two 10-meter-thick beds, three 6.67-meter-thick beds, four 5-meter-thick beds, and five 4meter-thick beds, which permits me to analyze the influence of planar bedding upon the stress and strain fields within the beds. Additionally, I vary the coefficient of friction between the beds, which permits me to assess the influence of inter-layer friction upon stress and strain field development.

Initial Step. The initial analysis describes position constraints, contacts, and material properties of the model. Within my analysis, boundary conditions as well as material properties are defined within the initial step are propagated throughout the subsequent analysis steps. Following the strategy Dietrich and Decker (1975) used, fixed boundaries are placed far from the area of deformation analysis, so that the restrained nodes do not affect the analysis.

Displacement Step. During the displacement step, I apply an inward force to the unpinned (left) side of the model. Using a pre-defined stress of $29.88 \mathrm{~Pa}$, this inward force acts to simulate low horizontal $\left(\sigma_{3}\right)$ tectonic stress. Similarly, I use an inward (downward) force, applied to the top of the model, to simulate $\sigma_{1}$ (vertical force in Fig. 1). This force is pre-defined as 
105.92 $\mathrm{Pa}$. Along with these forces, I apply a matching $\left(\sigma_{1}=-105.92 \mathrm{~Pa} ; \sigma_{3}=-29.88 \mathrm{~Pa}\right)$ pre-defined stress tensor to the elements of the entire model. This ensures that the model does not encounter computational issues arising from under-constrained boundary conditions.

Total displacement occurs through a series of increments, which add up to the prescribed total displacement magnitude of 0.125 meters (this displacement ensures that the test strata experience through-going plastic failure). I allow ABAQUS to choose how many increments are used for computational efficiency. Since I describe total displacement as a vector (magnitude and direction) rather than a true force, the number of increments used to apply the displacement does not affect the overall analysis in this discrete, quasi-static analysis.

\section{Analysis of Output Variables}

For each model iteration, I analyze the location at which the test beds exhibit initial plastic failure. Additionally, I consider the amount of displacement necessary to cause initial plastic failure. Then, I analyze the distribution of maximum principal in-plane stress within the test beds at the level of displacement, measured at the point where the corner of the footwall fault block (B1) contacts the test strata and first plastic failure occurs. These output variables allow me to identify spatial patters of stress accumulation. Additionally, I analyze the maximum principal in-plane stress vectors before and after initial plastic failure. These vector values allow me to characterize the development of stress during initial phases of displacement.

Finally, I analyze the spatial distribution of maximum principal in-plane stress and strain at the level of displacement that causes through-going failure to occur through the entire section of test strata. Identifying the moment of through-going failure is not straightforward, as the spatial distribution of failure throughout the test strata may not form a continuous line. So, I define through-going failure as the "moment" when a line of direct contact between failed 
elements forms through the entire package of test strata. At this point, the fault tip has propagated through the entire test section.

\section{DATA AND RESULTS}

\section{Initial Plastic Failure}

For each iteration of the model, initial plastic failure occurred at displacements between 0.030 meters and 0.040 meters (Fig. 3; additional results can be found in Appendix). Models failed at one or two regions within the model, (Fig. 4), with failure restricted to the lowermost and uppermost layers of the test package (Fig. 4). This pattern of localized failure occurred in all models. This means that, where simultaneous initial failure occurred, initial plastic failure occurred close to the propagating fault tip (1-4 meters from the fault tip) as well as up to 19 meters from the propagating tip. The distribution of simultaneous initial failure, where three or more beds were deformed, is symmetrical about the center of the test strata (Fig.4). Increasing the number of beds generally increases the total area that fails during initial plastic failure. For example, when friction was held constant, the total area that initially failed in the model with one bed was less than $1 \mathrm{~m}^{2}$, while the total area that failed in the model with five beds was more than $5 \mathrm{~m}^{2}$ (Fig. 4). Varying the coefficient of friction between test beds did alters the distribution of initial plastic failure; generally, models with lower friction between beds had a larger total area of plastic failure (Figs. A1-A4 in Appendix). For the models with two test beds, varying the coefficient of friction between test beds alters the displacement necessary to cause initial plastic failure, but this effect does not hold true for other models (Fig. 3). 


\section{Displacement Causing Initial Plastic Failure}

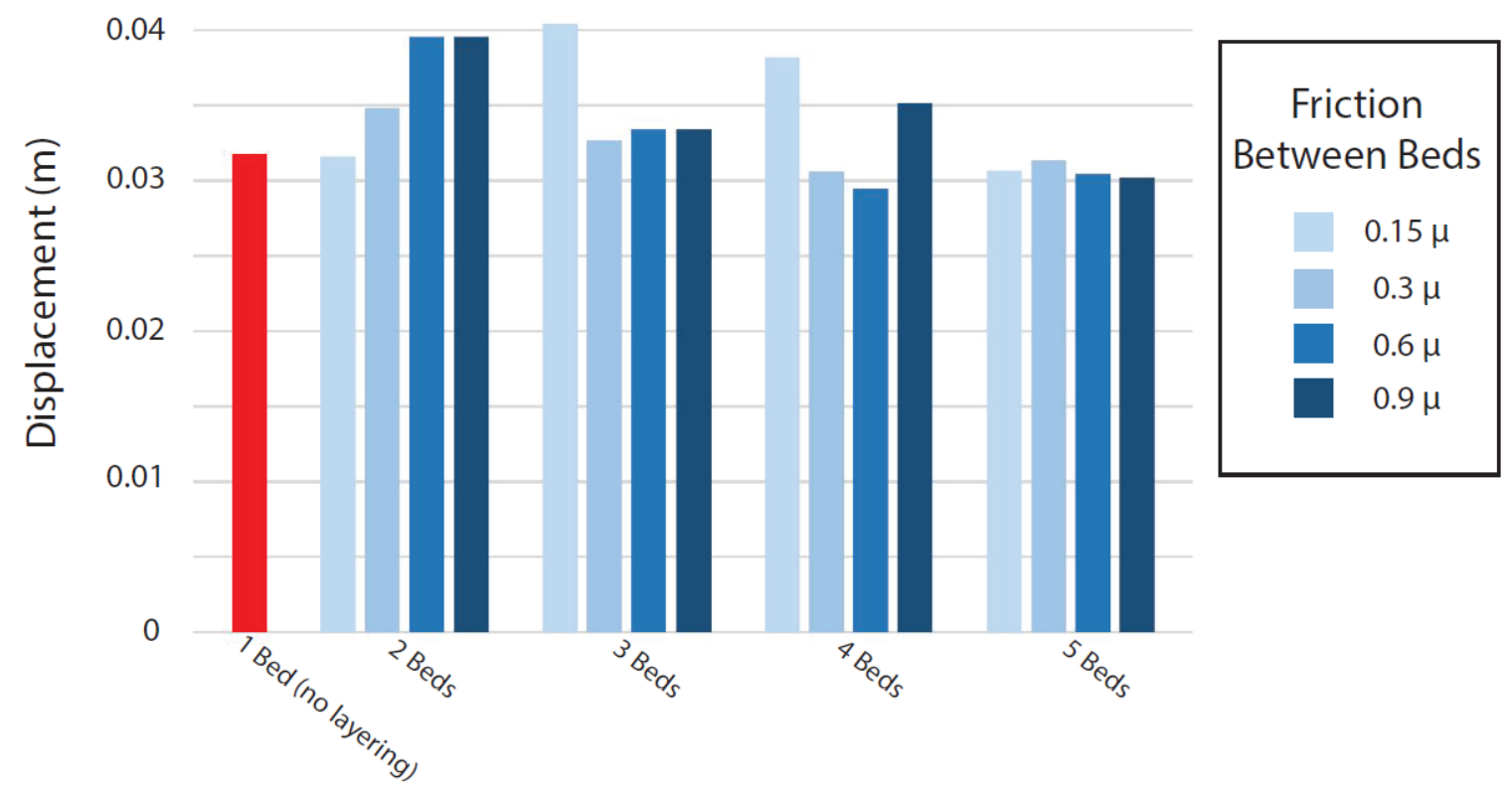

Figure 2. Amount of displacement necessary to cause plastic failure in each model. The models are clustered along the x-axis by the number of beds present and color-coded by the friction between beds (increasing friction is a darker hue). Note that friction does not affect the amount of displacement required to cause plastic failure. Note that all models failed within $0.01 \mathrm{~m}$ from one another, at three to four cm of displacement. 


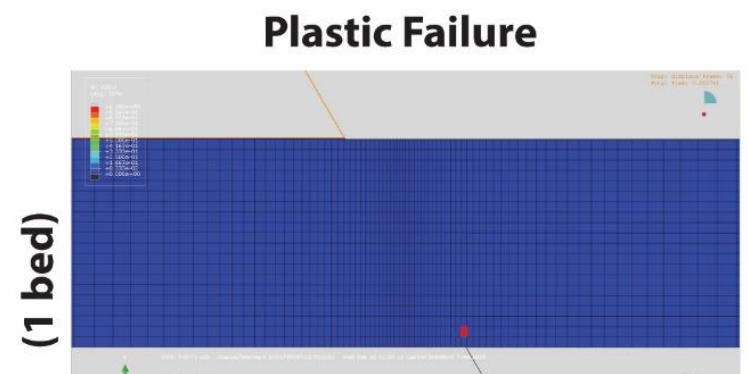

\section{Max. In-Plane Principal Stress}

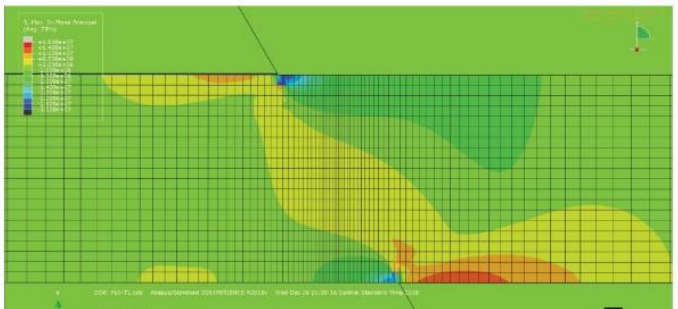

A

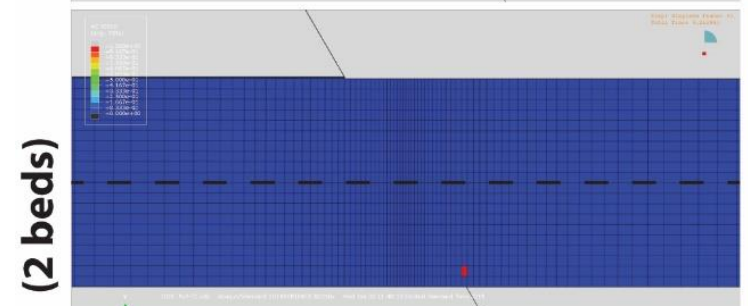

L

B
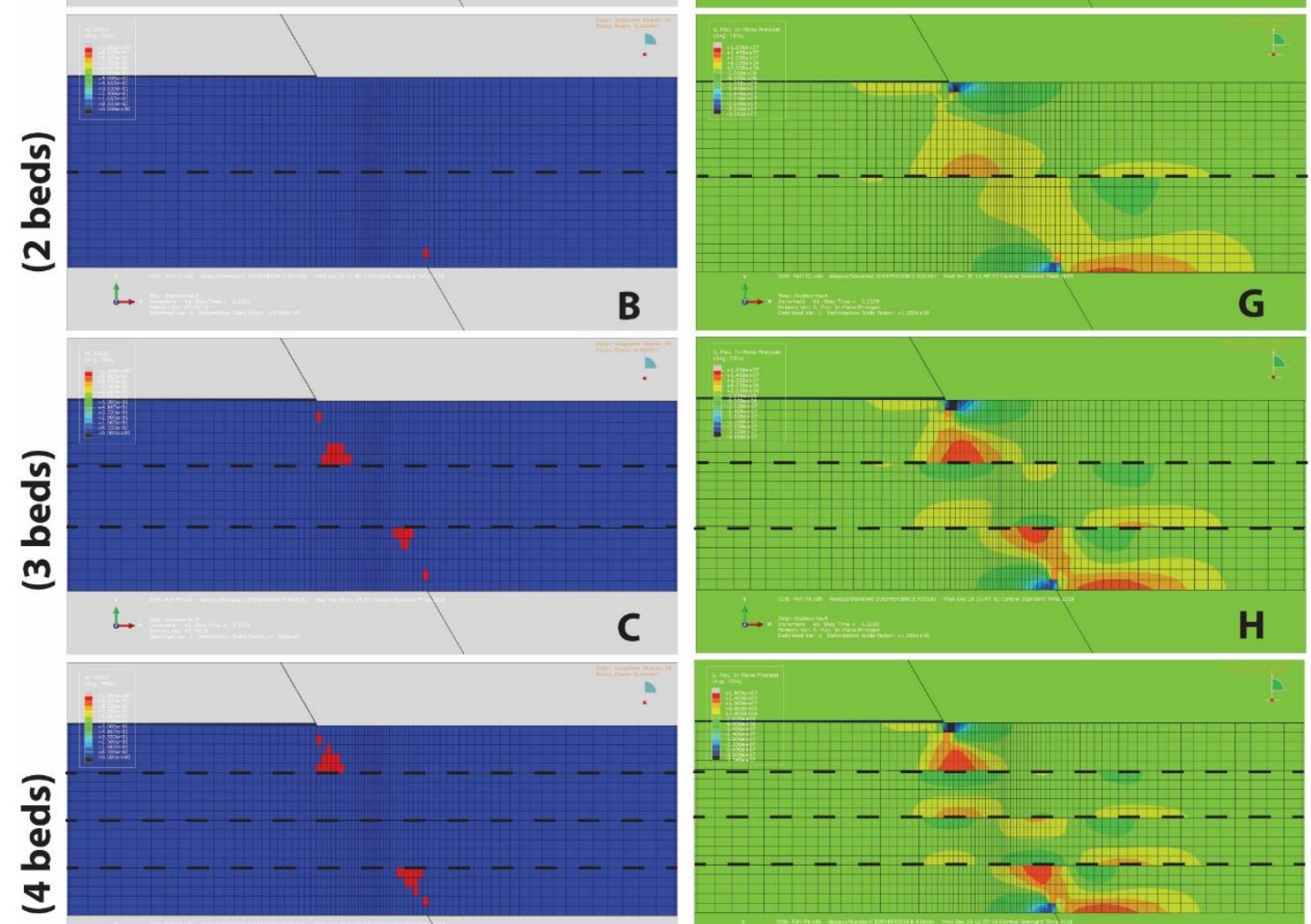

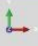

D
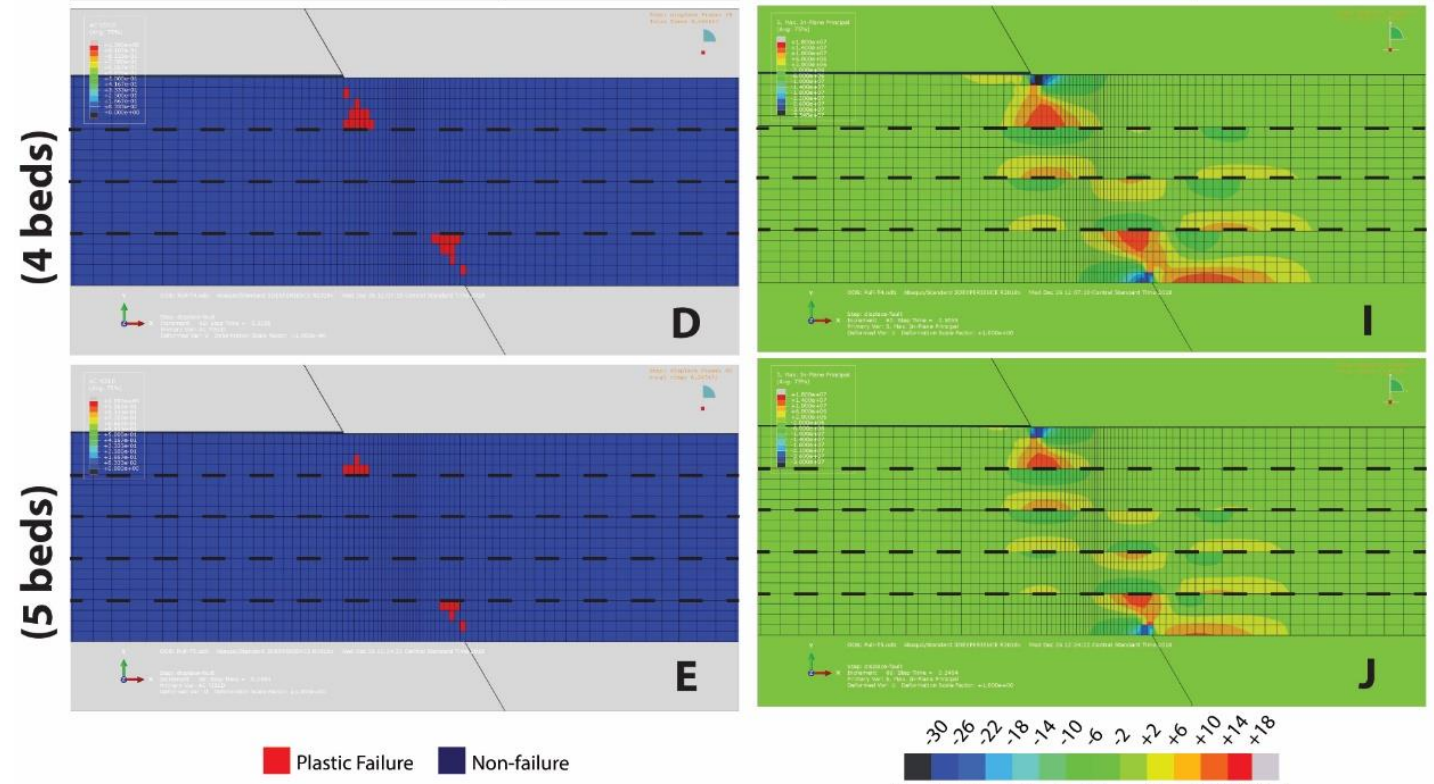

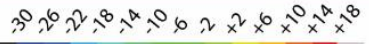

Max. In-plane Principal Stress (Avg: 75\%)(MPa)

Figure 3. Initial plastic failure $(A-E)$ and stress gradients $(F-J)$ at low levels of displacement, with constant friction between beds $(0.15 \mu)$. Dashed lines indicate bedding planes. Note that the presence of three or more beds $(C-E)$ results in multiple locations of simultaneous plastic failure and that initial failure is confined to the lowermost and uppermost mechanical layers in each model (A$E)$. Also note that mechanical layering $(G$ through $J)$ distorts the smooth gradient seen when no layering is present $(F)$. Finally, note that by increasing the number of mechanical layers, higher stress concentrations are focused near the center of the test strata $(G-J)$. Positive stress values are tensional, negative values are compressional. Each model is shown at displacement causing initial plastic failure; thus, each model is of similar, but not equal, displacement. 


\section{Initial Stress Distribution}

At displacements causing initial

plastic failure, maximum tensile in-plane

principal stress is highest in the uppermost

and lowermost mechanical layers, reaching

values ranging from 11.4 MPa to $14.2 \mathrm{MPa}$

(Fig. 4). Furthermore, the total area of

elevated (> $6 \mathrm{MPa}$ ) tensile stress is greater in the hanging wall of the projected fault plane

than in the footwall at constant $(0.15 \mu)$

friction (Fig. 4). In all models at low levels of displacement and constant (0.15) coefficient of friction $(\mu)$, the ratio of area of elevated (> $6 \mathrm{MPa}$ ) tensile stress in the hanging wall to the footwall was ranged from 1.4:1 (five beds) to 9.8:1 (1 bed) (Table 2).

When only one bed is present, inplane principal tensile stress is highest in the base of the hanging wall of the bed, where the model contact the lower right bounding block (Fig. 4). The model with one bed exhibits a smooth stress gradient ahead of the propagating fault tip that reaches a localized

\section{Max. In-Plane Principal Stress}
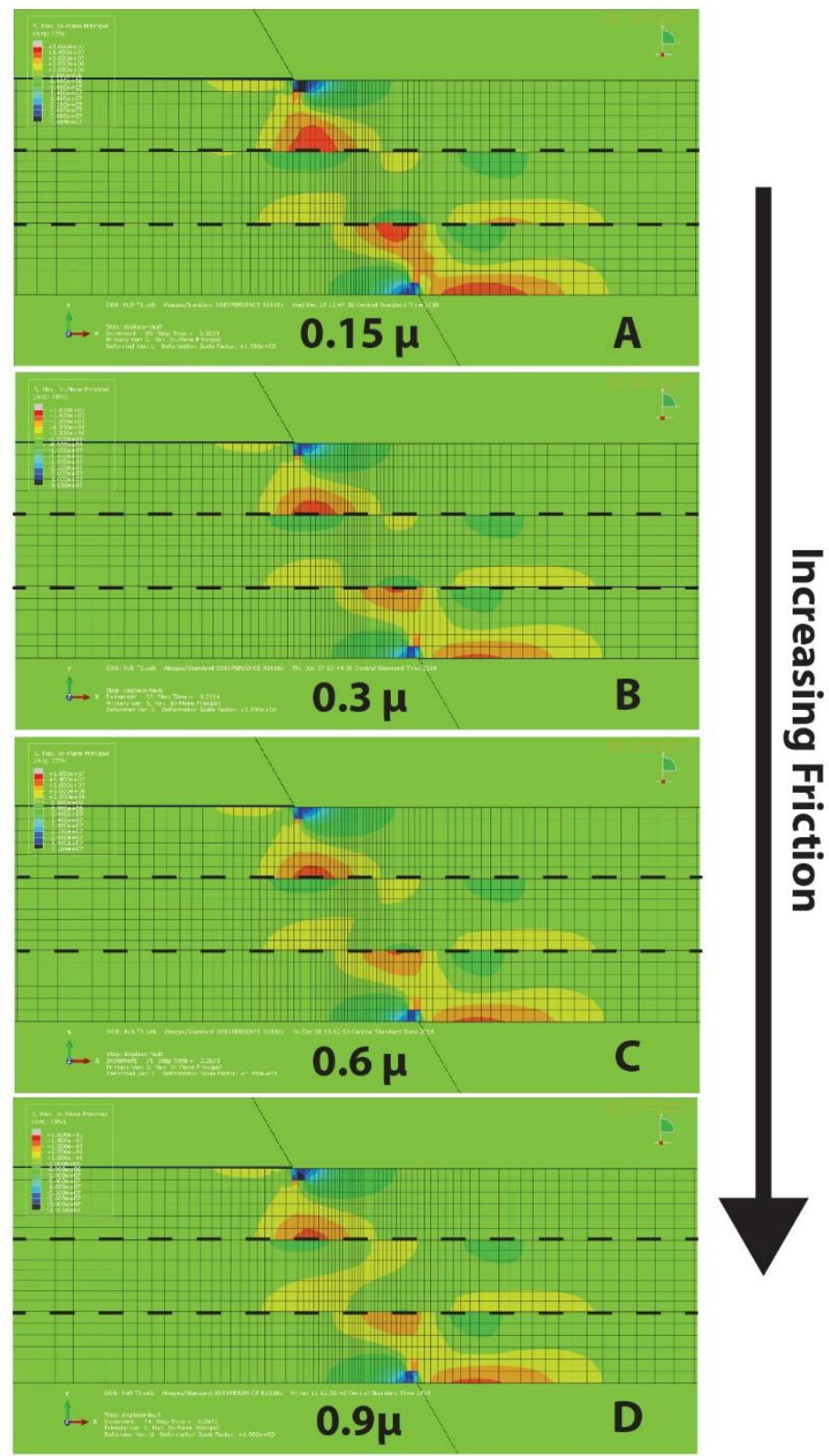

$3^{0} \lambda^{6} \lambda^{2} ?^{8}, x^{\alpha}, 062 x^{2} x^{6} x^{0} x^{\alpha} x^{80}$

Max. In-plane Principal Stress (Avg: 75\%)(MPa)

Figure 4. Comparison of maximum in-plane principal stress distributions through three beds at low levels of displacement. Note that as the coefficient of friction between beds is increased, a more continuous gradient of stress develops through the strata. Positive stress values are tensional, negative values are compressional. Each model is shown at displacement causing initial plastic failure; thus, each model is of similar, but not equal, displacement. 
maximum tensile in-plane principal stress of 13.2 MPa (Fig. 4). The total area of elevated (> 6 $\mathrm{MPa}$ ) tensile stress, in the model with only one bed, reached $47.7 \mathrm{~m}^{2}$ (Table 2).

When mechanical layering is present, the smooth in-plane stress gradient becomes discontinuous, strongly affected by boundaries between mechanical layers (Fig. 4). In-plane principal tensile stress near the center of the multi-bed package of test strata (in the center of the model) is elevated relative to the level of stress in the center of the single bed model. However, increasing the number of beds does not affect the total area of elevated (> $6 \mathrm{MPa}$ ) tensile stress under low levels of displacement (Table 2). Increased friction between mechanical layers results in the development of a more continuous gradient of in-plane principal stress from one mechanical boundary to the next, but increased friction does not increase the maximum value of localized in-plane principal tensile stress achieved (Fig. 5).

Table 2. Area of elevated tensile stress at low displacement with constant (0.15) coefficient of friction $(\mu)$.

\begin{tabular}{|c|c|c|c|c|}
\hline Model & $\begin{array}{c}\text { Area of (>6 MPa) Stress } \\
\text { in Hanging Wall } \\
\left(\mathbf{m}^{2}\right)\end{array}$ & $\begin{array}{c}\text { Area of (>6 MPa) } \\
\text { Stress in Footwall } \\
\left(\mathbf{m}^{2}\right)\end{array}$ & $\begin{array}{c}\text { Ratio of Stress in } \\
\text { Hanging Wall to } \\
\text { Footwall }\end{array}$ & $\begin{array}{c}\text { Total Area of } \\
(>\mathbf{6} \text { MPa }) \\
\text { Stress } \\
\left(\mathbf{m}^{\mathbf{2}}\right)\end{array}$ \\
\hline $\mathbf{1}$ Bed & 43.3 & 4.4 & $9.8: 1$ & 47.7 \\
\hline $\mathbf{2}$ Beds & 22.6 & 13.8 & $1.6: 1$ & 36.4 \\
\hline $\mathbf{3}$ Beds & 39.7 & 23.5 & $1.7: 1$ & 63.2 \\
\hline $\mathbf{4}$ Beds & 37.0 & 20.4 & $1.8: 1$ & 57.4 \\
\hline $\mathbf{5}$ Beds & 20.9 & 14.5 & $1.4: 1$ & 35.4 \\
\hline
\end{tabular}




\section{Initial Plastic Strain Distribution and Development}

When only one mechanical layer is deformed in the model, increased displacement leads to a smooth, along-fault-plane accumulation of in-plane principal strain ahead of the fault tip. Low levels (between 5E-5 and $1.1 \mathrm{E}-3$ ) of strain preferentially accumulate along the lower boundary of the hanging wall and the upper boundary of the footwall, where the beds contact the bounding blocks (Fig. 6). Additionally, low levels of strain accumulate over a greater area in the hanging wall (off the fault plane) than in the footwall (Fig. 6). This accumulation of strain matches the spatial distribution of stress that occurs under the same conditions (Fig. 4), but elevated (>1.1E-3) strain is confined to a smaller area than elevated stress (Fig. 6).

At displacement levels causing initial plastic failure, the presence of mechanical layering discretizes strain at the mechanical boundaries (Fig. 6). In every model with mechanical layering, in-plane principal strain is maximized in the uppermost and lowermost

mechanical layers as well as along contacts between beds (similarly indicated by the location of initial plastic failure) (Fig. 6). However, the development of strain

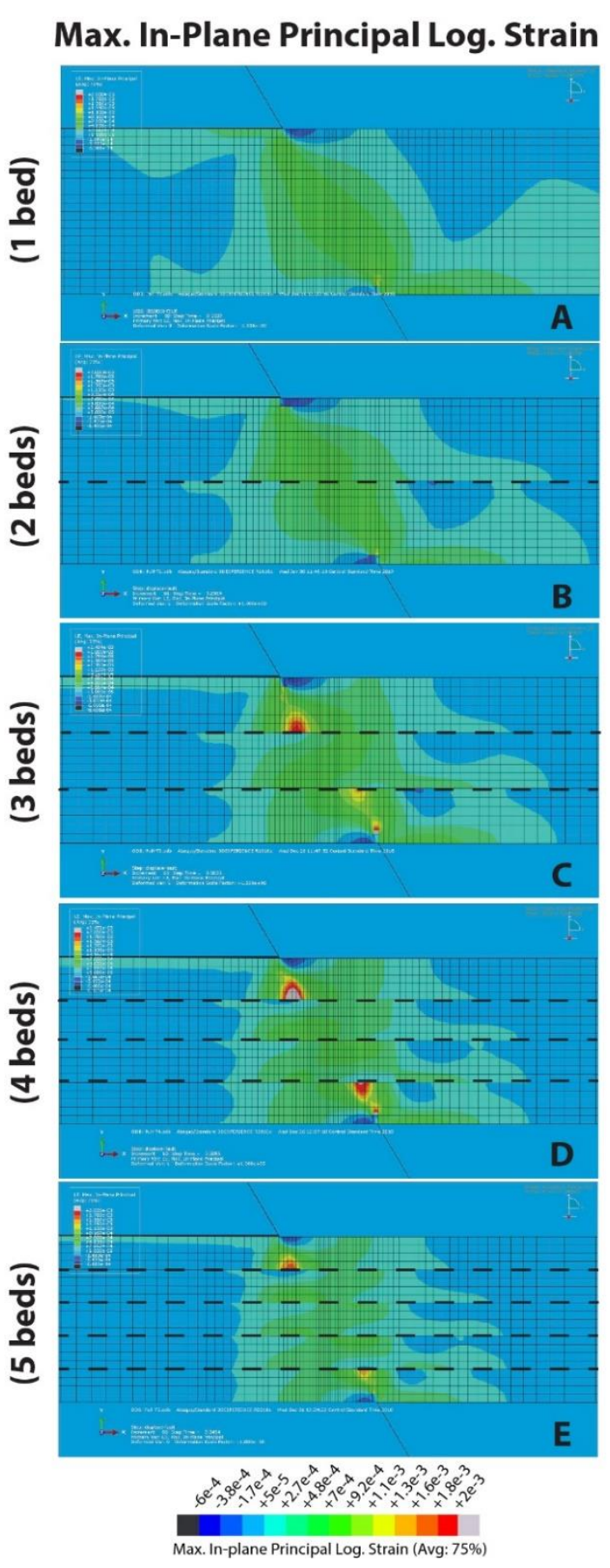

Figure 5. Maximum in-plane principal logarithmic strain distribution at low levels of displacement and constant $(0.15)$ coefficient of friction $(\mu)$ between beds. Dashed line indicates bedding plane. Note that where three or more layers are present $(C-E)$, maximum values of strain are localized to the outer most beds. Additionally, elevated strain is confined to a relatively small area. Each model is shown at the displacement causing initial plastic failure; thus, each model is of similar, but not equal, displacement. 
across layer boundaries is generally more continuous than the accumulation of stress (Fig 6; Fig. 4). At low levels of displacement (0.03-0.04 m), the maximum in-plane strain ranged from 1.3E3 to 2.7E-3 (Table 2). With increased displacement $(0.07-0.09 \mathrm{~m})$, maximum in-plane strain ranged from 1.2E-2 to 2.6E-2 (Table 2).

Table 2. Maximum stress and strain achieved in each model

\begin{tabular}{|c|c|c|c|c|}
\hline \multirow{2}{*}{$\begin{array}{c}\text { Maximum Value } \\
\text { Across Entire } \\
\text { Test Section }\end{array}$} & \multicolumn{2}{|c|}{ Low (0.03-0.04 m) Displacement } & \multicolumn{2}{|c|}{ Increased (0.07-0.09 m) Displacement } \\
\hline & $\begin{array}{l}\text { Max. Log. In- } \\
\text { Plane Principal } \\
\text { Strain }\end{array}$ & $\begin{array}{c}\text { Max. In-Plane } \\
\text { Principal Stress } \\
\text { (MPa) }\end{array}$ & $\begin{array}{l}\text { Maximum Log. } \\
\text { In-Plane } \\
\text { Principal Strain }\end{array}$ & $\begin{array}{c}\text { Max. In-Plane } \\
\text { Principal Stress } \\
\text { (MPa) }\end{array}$ \\
\hline $\begin{array}{l}1 \text { Bed (No } \\
\text { Layering) }\end{array}$ & $1.70 \mathrm{E}-3$ & 13.2 & $2.61 \mathrm{E}-2$ & 18.1 \\
\hline 2 Beds $(0.15 \mu)$ & $1.26 \mathrm{E}-3$ & 11.4 & $2.18 \mathrm{E}-2$ & 18.0 \\
\hline 2 Beds $(0.3 \mu)$ & $1.73 \mathrm{E}-3$ & 12.5 & $1.91 \mathrm{E}-2$ & 18.0 \\
\hline 2 Beds $(0.6 \mu)$ & $2.43 \mathrm{E}-3$ & 14.2 & $1.20 \mathrm{E}-2$ & 18.0 \\
\hline 2 Beds $(0.9 \mu)$ & $2.44 \mathrm{E}-3$ & 14.2 & N/A & N/A \\
\hline 3 Beds $(0.15 \mu)$ & $2.49 \mathrm{E}-3$ & 13.8 & $2.54 \mathrm{E}-2$ & 18.0 \\
\hline 3 Beds $(0.3 \mu)$ & $1.26 \mathrm{E}-3$ & 12.8 & $1.96 \mathrm{E}-2$ & 18.0 \\
\hline 3 Beds $(0.6 \mu)$ & $1.36 \mathrm{E}-3$ & 12.5 & $1.43 \mathrm{E}-2$ & 18.0 \\
\hline 3 Beds $(0.9 \mu)$ & $1.34 \mathrm{E}-3$ & 11.8 & $1.14 \mathrm{E}-2$ & 18.0 \\
\hline 4 Beds $(0.15 \mu)$ & $2.71 \mathrm{E}-3$ & 13.8 & $3.41 \mathrm{E}-2$ & 18.0 \\
\hline 4 Beds $(0.3 \mu)$ & $1.55 \mathrm{E}-3$ & 13.2 & $2.28 \mathrm{E}-2$ & 18.0 \\
\hline 4 Beds $(0.6 \mu)$ & $1.29 \mathrm{E}-3$ & 13.2 & $1.65 \mathrm{E}-2$ & 18.0 \\
\hline 4 Beds $(0.9 \mu)$ & $1.65 \mathrm{E}-3$ & 12.3 & $1.29 \mathrm{E}-2$ & 18.0 \\
\hline 5 Beds $(0.15 \mu)$ & $1.96 \mathrm{E}-3$ & 13.2 & $2.52 \mathrm{E}-2$ & 18.0 \\
\hline 5 Beds $(0.3 \mu)$ & $1.90 \mathrm{E}-3$ & 13.0 & $2.20 \mathrm{E}-2$ & 18.0 \\
\hline 5 Beds $(0.6 \mu)$ & $1.49 \mathrm{E}-3$ & 13.0 & $1.65 \mathrm{E}-2$ & 18.0 \\
\hline 5 Beds $(0.9 \mu)$ & $1.30 \mathrm{E}-3$ & 12.9 & $1.33 \mathrm{E}-2$ & 18.0 \\
\hline
\end{tabular}




\section{Through-going Plastic Failure}

With continued displacement $(0.07$ to $0.09 \mathrm{~m})$, through-going plastic failure occurred throughout the entire $20 \mathrm{~m}$ test section (Fig. 7). In all models, at these levels of displacement, plastic failure occurs laterally along the base of the test strata in the hanging wall, where the test strata contacts bounding block B2 (Fig. 7). Where only one bed was present, failure is synthetic to the fault plane, and with a strain distribution that widens moderately up-section from the propagating fault (Fig. 7; e.g. Seog et al., 2004). In models with more than two beds, additional failure occurs off-fault-plane along mechanical layer boundaries in the hanging wall of test strata (Fig. 7; e.g., Seog et al. 2004).

\section{Through-going Stress Distribution}

At displacement causing through-going failure (0.07 to $0.09 \mathrm{~m})$, stress gradients ahead of the propagating fault tip become less discontinuous than in the earliest stages of propagation (Fig. 7), with stress relatively concentrated along the plane of the propagating fault. At this level of displacement, regions of elevated (> $6 \mathrm{MPa}$ ) tensile stress occur more frequently in the hanging wall than in the footwall (Fig. 7); off-fault-plane distributions of elevated tensile stress occur within 5 meters of the fault plane in the lowermost beds and occur further from the fault plane in the uppermost beds, where they occur more than 10 meters from the fault plane, measured parallel to bedding (Fig. 8). With increasing friction between layers, the center of offfault-plane stress concentrations are farther from the fault plane; this is best quantified by specifying the angle between the fault plane and a line running through the center of the offfault-plane stress concentration (Fig. 8). All models with mechanical layering reached a localized maximum tensile in-plane principal stress of $18 \mathrm{MPa}$. In the model with no layering, the maximum tensile in-plane principal stress achieved was slightly higher, at 18.1 MPa (Table 2). 


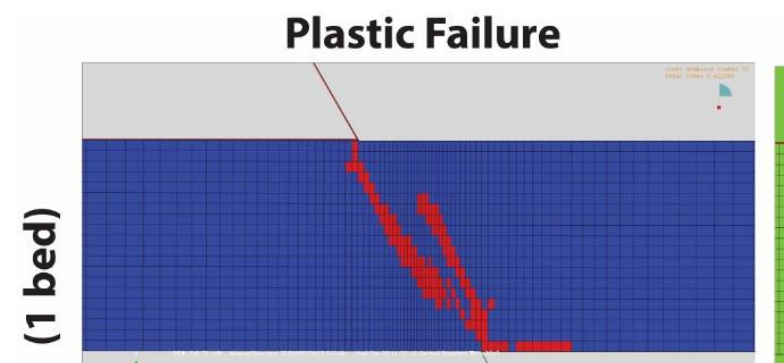

$L=-1$

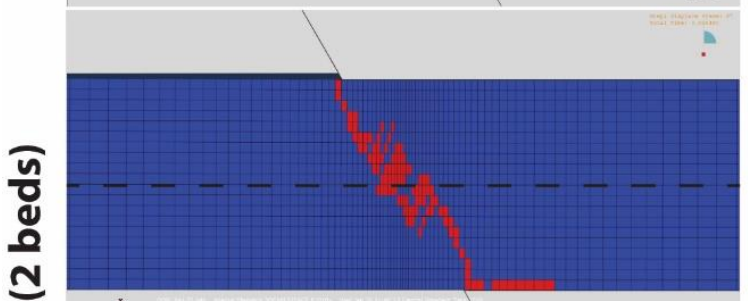

L. B B

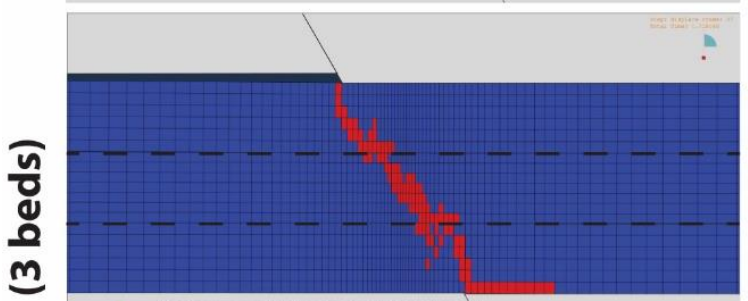

L $=\mathrm{C}$

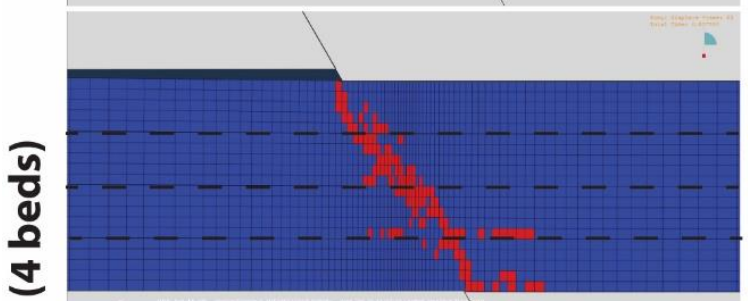

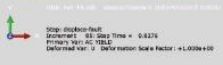

D

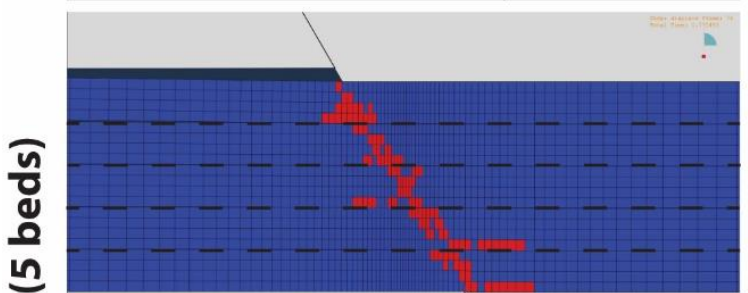

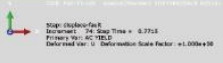

Plastic Failure
A
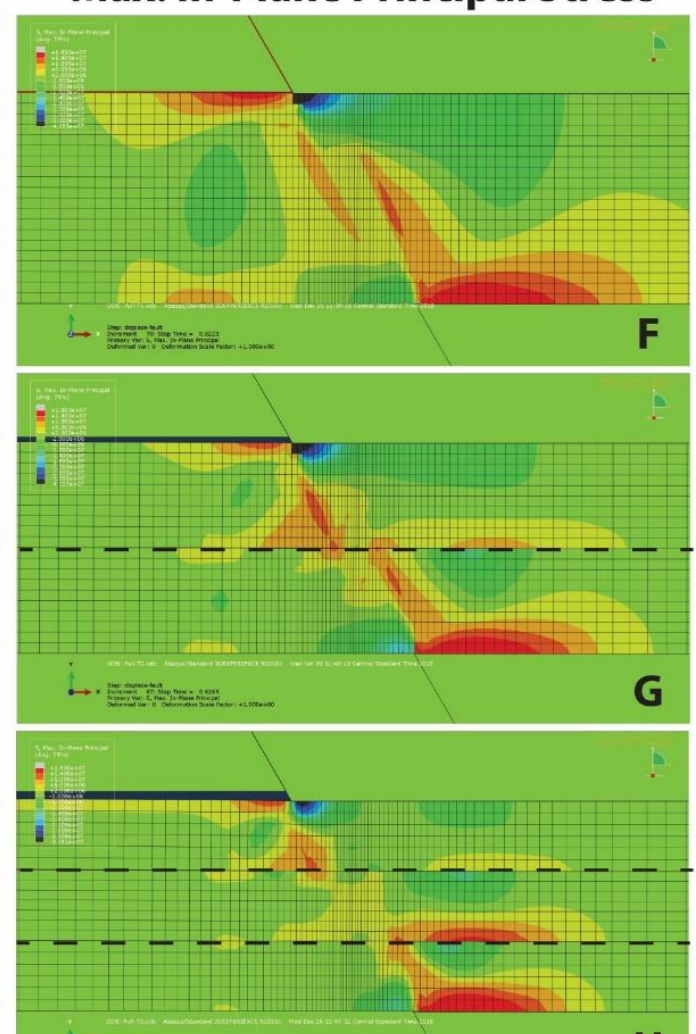

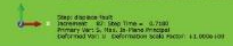

H
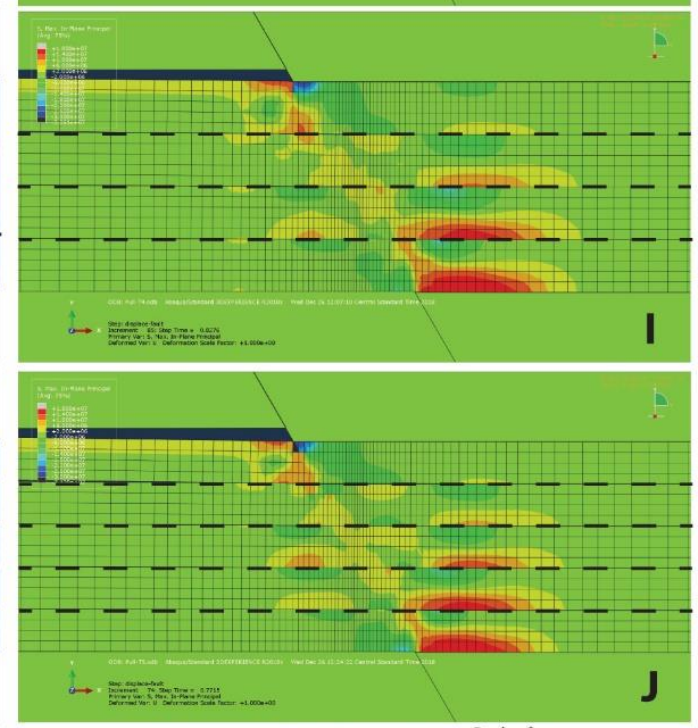

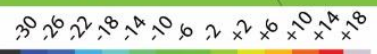

Max. In-plane Principal Stress (Avg: 75\%)(MPa)

Figure 6. Plastic failure $(A-E)$ and stress gradients $(F-J)$ at levels of displacement that cause through-going plastic failure, with constant friction between layers $(0.15 \mu)$. Dashed line indicates bedding plane. Note that in a single bed (A), failure is fault-sub-parallel, but the presence of four or more beds $(D \& E)$ results in plastic failure along bedding planes. Note that failure accumulates where the hanging wall contacts the grey fault block $(A-E)$. Note that mechanical layering $(G-J)$ distorts the smooth stress gradient seen when no layering is present $(F)$. Note how increasing mechanical layering allows for increased stress concentrations off-plane from the fault, in the hanging wall (F-J). Finally, note the gap opening in the top left of each model; I discuss this geometric artifact in the "Geometric Limitations" section. Positive stress values are tensional, negative values are compressional. Each model is shown at the displacement causing through-going plastic failure; thus, each model is of similar, but not equal, displacement. 


\section{Max. In-Plane Principal Stress}

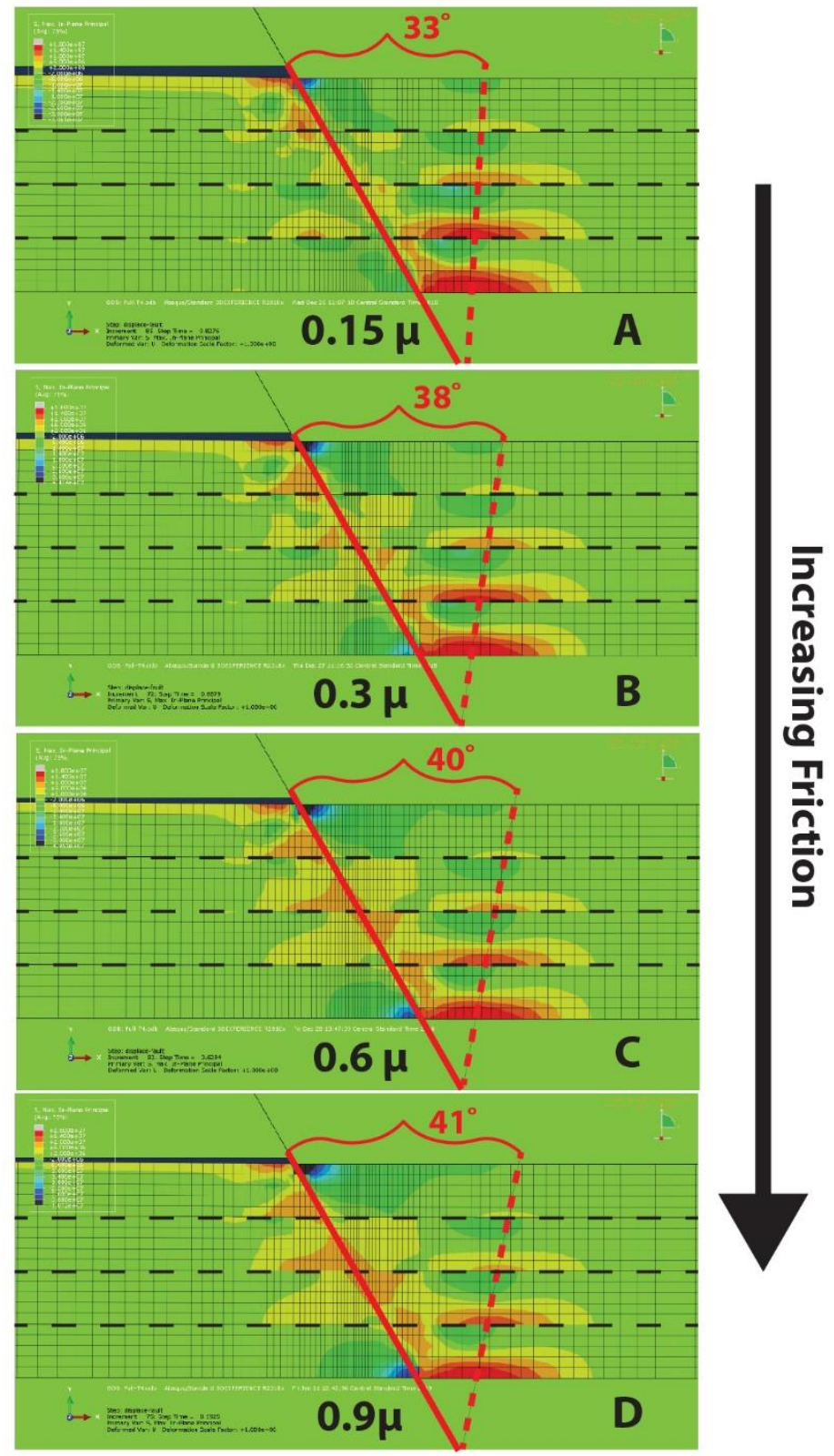

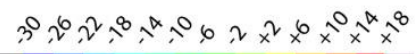

Max. In-plane Principal Stress (Avg: 75\%)(MPa)

Figure 7. Off-fault-plane maximum in-plane principal stress concentrations at increased displacement in models with four beds. Dashed line indicates bedding plane. Note that increasing friction between beds increases the angle between the fault plane and the center of off-fault-plane stress concentrations. Positive stress values are tensional, negative values are compressional. Each model is shown at the displacement causing through-going plastic failure; thus, each model is of similar, but not equal, displacement. 


\section{Limitations of Normal Fault Propagation Model Results}

I used finite modeling to examine the effect of mechanical layering (bedding planes) on normal fault propagation. ABAQUS/Standard provides a reasonable tool to model fault propagation, but modeling choices heavily affect the output variables as well as whether or not a model will run to completion. Based on my modeling geometry, material properties, and boundary conditions, I tested 17 models. The majority modeled both initial plastic failure as well as through-going failure; only 1 model did not model through-going failure but did model initial stages of plastic failure. The model may not have run to through-failure for a variety of reasons, but mathematical convergence issues seems to have caused the model to end prematurely. Since I am most interested in the initial stages of plastic failure during fault propagation, these computational limitations did not affect my analysis; but they would become an issue during modeling of large fault movements.

\section{Geometric Limitations}

Because the boundary conditions of any given model must be specified and controlled in ABAQUS/Standard, my 2D model geometry allows for the reasonable displacements to be applied to the test strata but does not replicate real-world geometries. For example, for each model tested, after small displacements, the upper fault block of the footwall (fault block B3) begins to separate from the test strata near the fault. Such an opening would not happen in the real-world. The opening likely occurs because the four fault blocks (B1 through B4) were given perfectly elastic behaviors for modeling efficiency, as opposed to elastic-plastic behaviors of rocks in the real world; additionally, the low values I apply in the initial stress state permit the opening between the test strata and the bounding blocks. Although my results are not made irrelevant by this model behavior, my results may be influenced by this modeling artifact. For 
example, it is possible that the observed occurrence of initial plastic failure far ahead of the propagating fault tip may be a result of flexure of the beds permitted by the separation of the test strata from the bounding blocks. Additionally, the opening occurs because my model is unable to obtain true geostatic equilibrium before displacement. The tectonic and overburden force applied to the top and sides of the model is six orders of magnitude less than what might be expected in a real-world system at depth. This modeling simplification was made in order to allow the elements in the test beds, the focus of modeling presented here, to behave as expected (behaving as coherent sandstone bedding as described by the material properties); when I attempted to achieve true geostatic equilibrium before displacement, computational issues and unrealistic material behavior resulted (Smart, 2018). However, although low, these boundary stress values are consistent with those expected near the Earth's surface.

\section{Resolution of Results}

Since I let Abaqus determine the displacement incrementation relative to the total displacement throughout each model, the displacement increments are not constant across all models. However, I limited the maximum amount of displacement applied from one increment of a model to the next increment at 0.0125 meters ( $10 \%$ of the total displacement), which means that the resolution of displacement available for any given model is $10 \%$ of displacement.

Additionally, the size and distribution of the mesh I applied to the test strata limits the resolution at which plastic failure, stress, and strain can be interpreted. My mesh, near the propagating fault, gives 1-meter vertical resolution and sub-meter horizontal resolution. The mesh distribution also affects my ability to identify through-going failure. When mesh resolution is combined with the low displacement increment resolution, it is difficult to determine the precise displacement and location where through-going failure occurs. Yet, since the location 
and fault displacement at which through-going failure occurs is not the focus of my analysis (I focus on initial plastic failure), my analysis is not dependent upon a precise determination of the through-going failure.

\section{DISCUSSION}

I used 2D finite element modeling to assess the role of mechanical layering in the initial stages of normal fault tip propagation. By varying the number of mechanical layers present (one layer to five layers), I found that the presence of layers inhibits the development of a smooth stress gradient ahead of the propagating fault tip. This leads to simultaneous, discontinuous plastic failure at multiple locations ahead of the fault tip during the initial stages of propagation, where the presence of fewer beds results in plastic failure over a smaller area than with a greater number of beds. With the material properties defined to represent a $20 \mathrm{~m}$ thick test section of sandstone, I find that a displacement of 0.03 to 0.04 meters is sufficient to cause plastic failure.

With continued displacement $(0.07$ to $0.09 \mathrm{~m})$, through-going plastic failure occurred throughout the entire $20 \mathrm{~m}$ test section for all models (sans the one model that ran into computational errors before through-failure occurred). This increased displacement caused stress gradients ahead of the propagating fault tips to become more continuous than in the earliest stages of propagation. As such, by the time through-going failure occurred, elevated tensile stress began concentrating in-plane with the propagating fault. At all levels of displacement tested, the greatest concentrations of stress occurred off-fault-plane along bedding contacts.

I find that varying the coefficient of friction of the contacts between mechanical layers has minimal effect on the development of plastic failure; however, varying friction does affect the distribution of stress within the test strata. Increasing friction leads to a smoother stress gradient and minimizes the discontinuous localization of strain at mechanical layer boundaries. 
Under $0.07 \mathrm{~m}$ to $0.09 \mathrm{~m}$ displacement, increasing friction causes off-fault-plane stress

accumulations in the hanging wall to occur further from the fault plane, so that the angle between the fault plane and the elevated regions of stress increases with increasing friction; this means that at low levels of friction, off-fault-plane stress tends to accumulate a meter or two closer to the fault plane than at high levels of friction.

Using a finite element approach, Smart et al. (2009) show that interlayer slip constrains the development of strain within bedded strata; Comparing models in which slip between bedding was permitted to models in which beds were not allowed to slip, they found that the presence of interlayer slip permits the development of more localized strain patterns (Smart et al., 2009). Although I did not examine slip along bedding planes, it is likely that slip acts as a control for the stress and strain patters that developed within each of my models. Yet I found that varying the coefficient of friction between beds had minimal effect on the development of strain. I hypothesize that my results indicate that, at the magnitude of stress causing failure, small changes in the coefficient of friction between the beds have little effect, although increasing friction to the point where interlayer slip is essentially prevented would have an effect. Additionally, my results show that where more beds are present, friction between beds plays a greater role, such that both interlayer slip and the number of bedding planes present control the spatial development of strain in a bedded system.

\section{Field and Subsurface Exploration Applications}

My models suggest that the initial stages of fault tip propagation of a normal fault within a layered system are not characterized by linear stress gradients leading to in-plane plastic failure. Rather, the initial stages of propagation are characterized by complex patterns of stress accumulation. The presence of discontinuous regions of increased stress along layer boundaries 
leads to simultaneous plastic failure at multiple locations ahead of the propagating fault tip. This behavior has implications for predicting slip and geometry at fault tip damage zones. The presence of mechanical layering may permit the development of a structurally complex fault tip damage zone. Additionally, I found that increasing friction between bedding planes results in a greater angle between the fault plane and centers of increased off-fault-plane stress. This suggests that the friction between bedding planes is a structural control on the distance at which damage zone may develop perpendicular to the projected fault plane of a propagating fault tip (i.e., the angles I measured) because bedding controls the stress field ahead of a propagating fault (e.g., Seog et al., 2004). Based on my results, I would expect a higher coefficient of friction between bedding planes to result in the development of a broad damage zone ahead of a propagating tip, while I would expect a low coefficient of friction to result in a narrow damage zone. To test this, additional displacement could be applied to my models, to identify where plastic failure occurs in later stages of fault tip propagation.

Within a field setting or in subsurface fault systems, I would expect fracturing and potential fluid conduits, associated with opening mode fracturing, to develop where the projected plane of a propagating fault tip intersects bedding planes. In my model, these stress accumulations occurred in the hanging wall, but I would expect differing boundary conditions may lead to similar accumulations in the footwall. My results suggest that off-fault-plane fractures are likely to occur under opening-mode (tensile) stresses, similar to the layer-parallel extension noted in Smart et al.'s (2009) models. As such, these off-fault-plane regions of concentrated stress predict the development of fractures along bedding planes several meters away from the fault trace. 
As one of the first attempts to model the influence of planar bedding upon the stress and strain fields ahead of a propagating normal fault, these findings should be considered preliminary. However, these results reveal the power of finite element analysis to predict the distribution of fracture initiation relative to a fault propagating through bedding, which has implications for subsurface resource exploration. This study reveals the power of FEA modeling to predict the distribution of stress and strain fields near propagating faults. 


\section{APPENDIX}
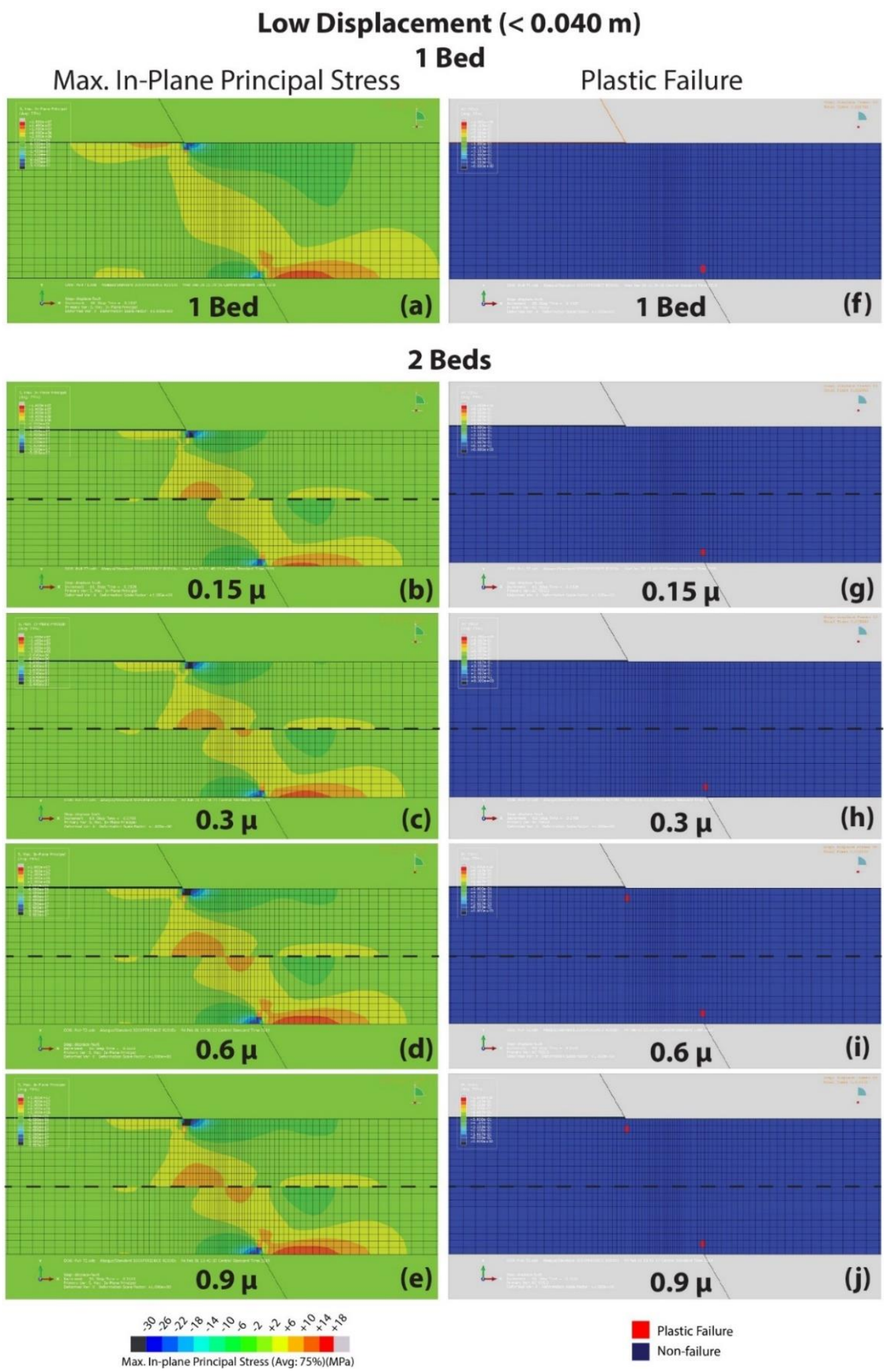

Figure A1. Stress gradients (a-e) and plastic failure $(f-j)$ at low levels of displacement, with increasing friction between one and two beds. Dashed line indicates bedding plane. Note that mechanical layering (b-e) distorts the smooth gradient seen when no layering is present (a); initial failure occurs near the outermost edges in each model $(f-j)$. Note how increasing the friction between beds allows for larger stress concentrations near the center of the test strata (b-e). Positive stress values are tensional, negative values are compressional. Each model is shown at the displacement causing initial plastic failure; thus, each model is of similar, but not equal, displacement. 


\section{Low Displacement $(<0.040 \mathrm{~m})$ 3 Beds}

Max. In-Plane Principal Stress
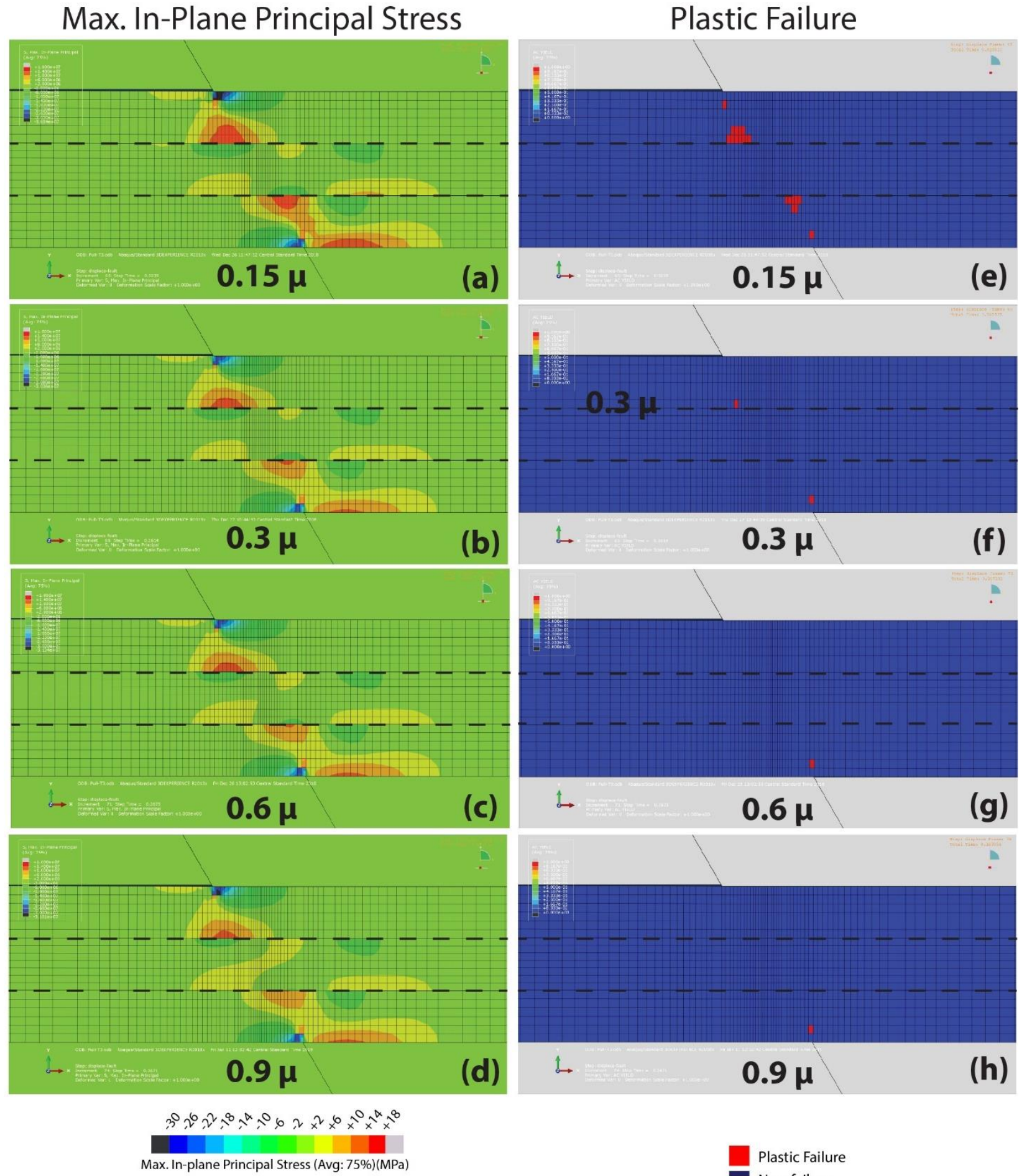

Plastic Failure

Non-failure

Figure A2. Stress gradients (a-d) and plastic failure (e-h) at low levels of displacement, with increasing friction between three beds. Dashed line indicates bedding plane. Note how increasing the friction between beds allows for larger stress concentrations near the center of the test strata $(a-d)$; initial failure is confined to the outermost beds in each model $(e-h)$. Positive stress values are tensional, negative values are

compressional. Each model is shown at the displacement causing initial plastic failure; thus, each model is of similar, but not equal, displacement. 


\section{Low Displacement $(<0.040 \mathrm{~m})$ 4 Beds}

Max. In-Plane Principal Stress
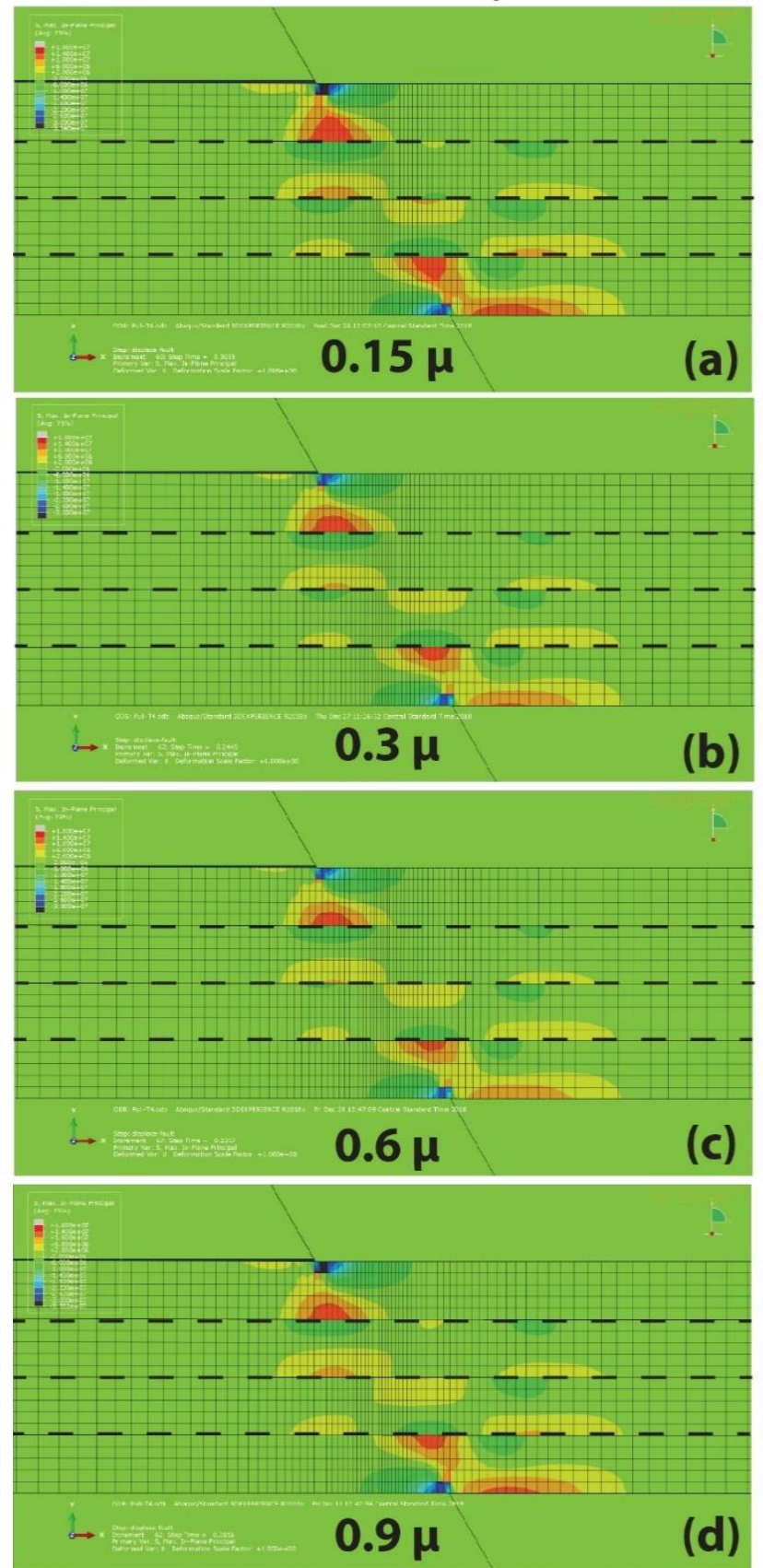

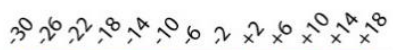

Plastic Failure

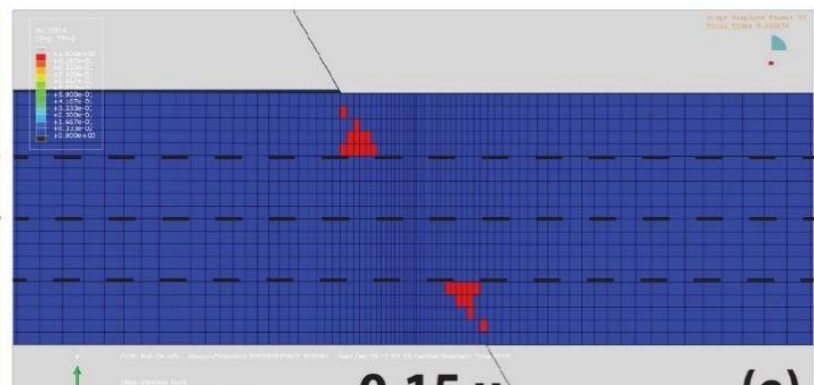

(e)

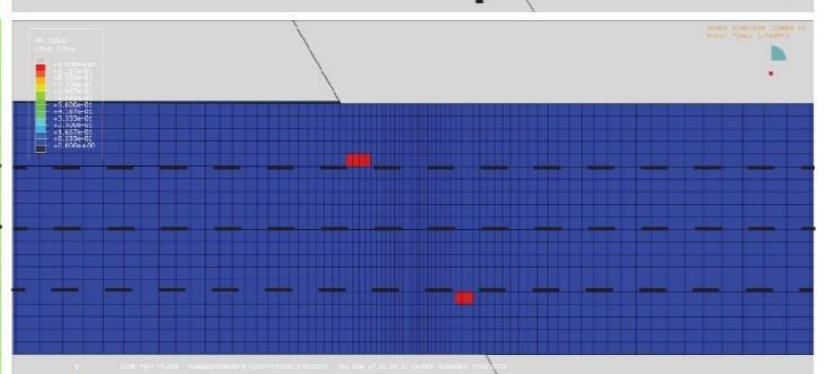

$\stackrel{\perp}{ } \quad 0.3 \mu$

(f)
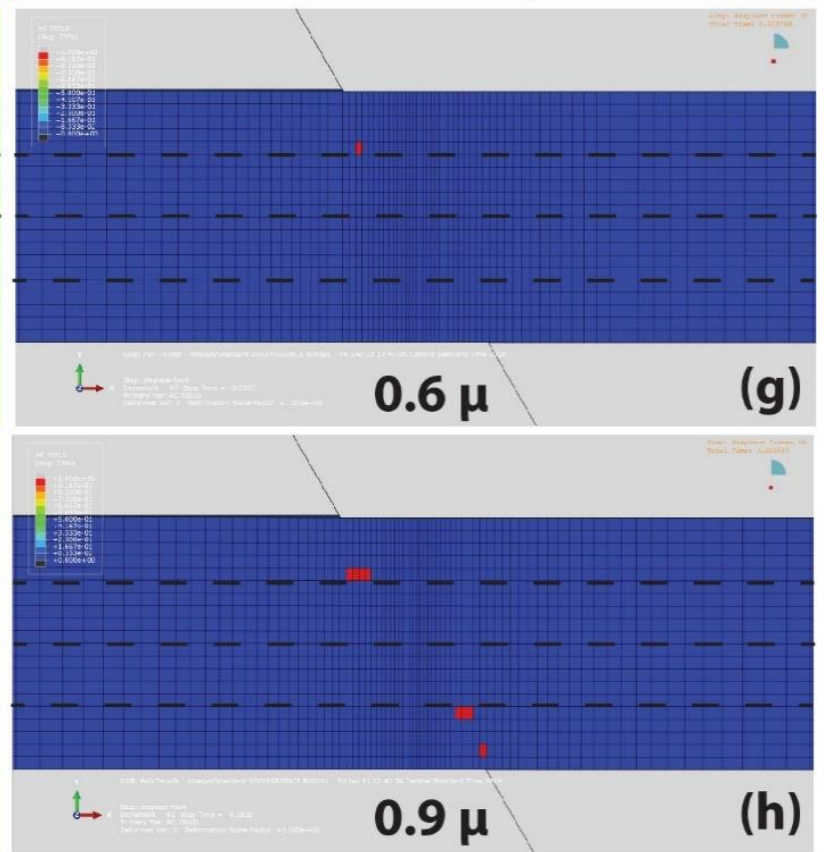

Plastic Failure

Non-failure

Figure A3. Stress gradients $(a-d)$ and plastic failure $(e-h)$ at low levels of displacement, with increasing friction between four beds. Dashed line indicates bedding plane. Note how increasing the friction between beds allows for larger stress concentrations near the center of the test strata $(a-d)$; initial failure is confined to the outermost beds in each model $(e-h)$. Note the off-fault-plane accumulations of stress $(a-d)$. Positive stress values are tensional, negative values are compressional. Each model is shown at the displacement causing initial plastic failure; thus, each model is of similar, but not equal, displacement. 


\section{Low Displacement $(<0.040 \mathrm{~m})$ 5 Beds}

Max. In-Plane Principal Stress
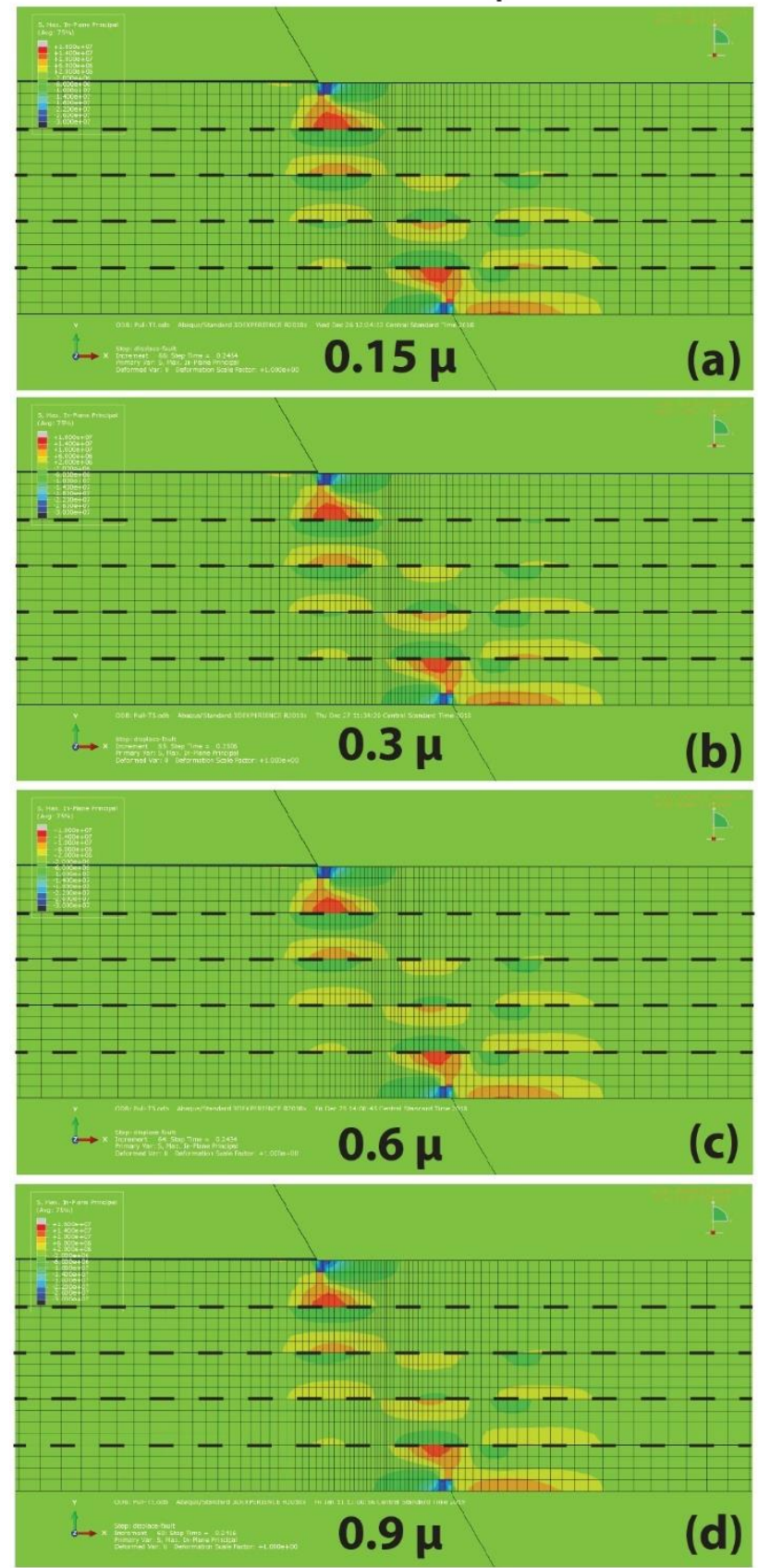

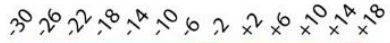

Max. In-plane Principal Stress (Avg: 75\%)(MPa)
Plastic Failure
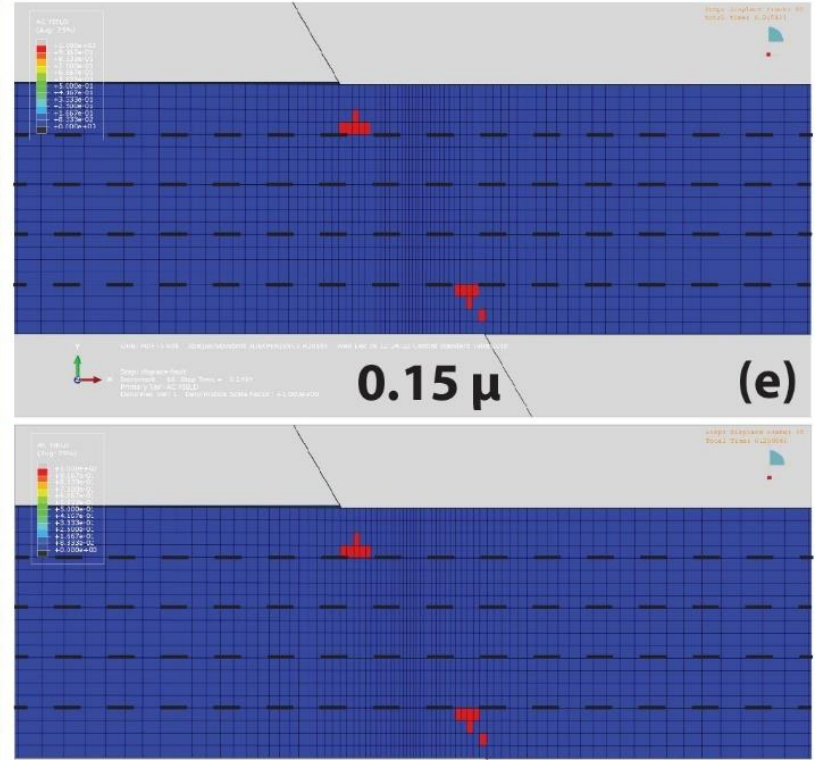

$\stackrel{\llcorner}{\leftrightarrow} \quad 0.3 \mu$

(f)
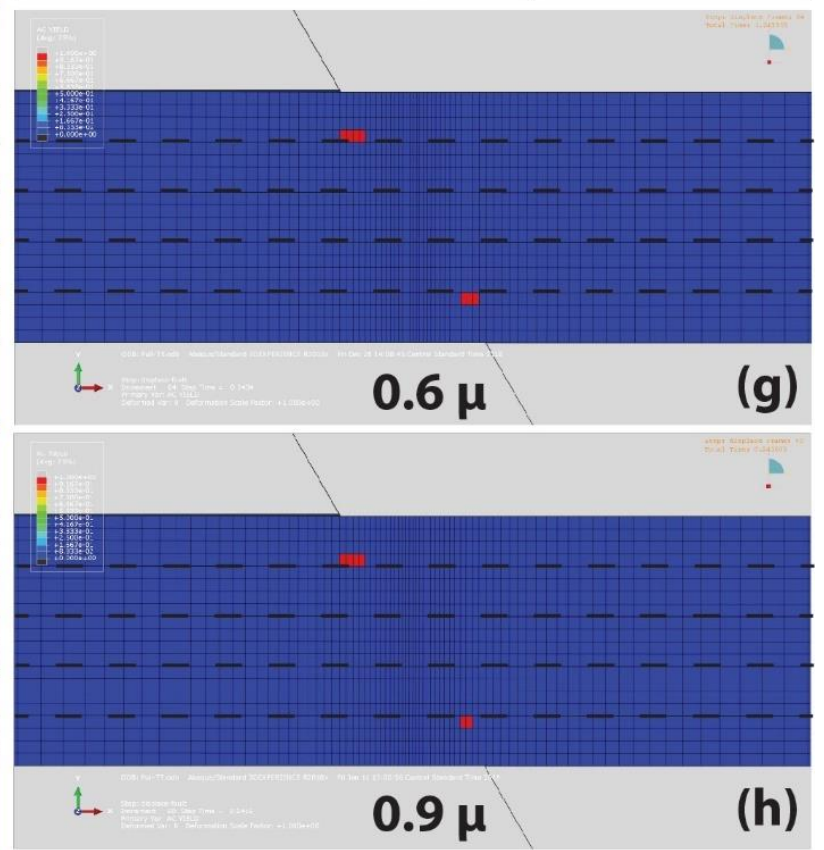

(h)

Figure A4. Stress gradients $(a-d)$ and plastic failure (e-h) at low levels of displacement, with increasing friction between five beds. Dashed line indicates bedding plane. Note how increasing the friction between beds allows for larger stress concentrations near the center of the test strata $(a-d)$; initial failure is confined to the outermost beds in each model $(e-h)$. Note the off-fault-plane accumulations of stress $(a-d)$. Positive stress values are tensional, negative values are compressional. Each model is shown at the displacement causing initial plastic failure; thus, each model is of similar, but not equal, displacement. 


\section{Low Displacement $(<0.040 \mathrm{~m})$}
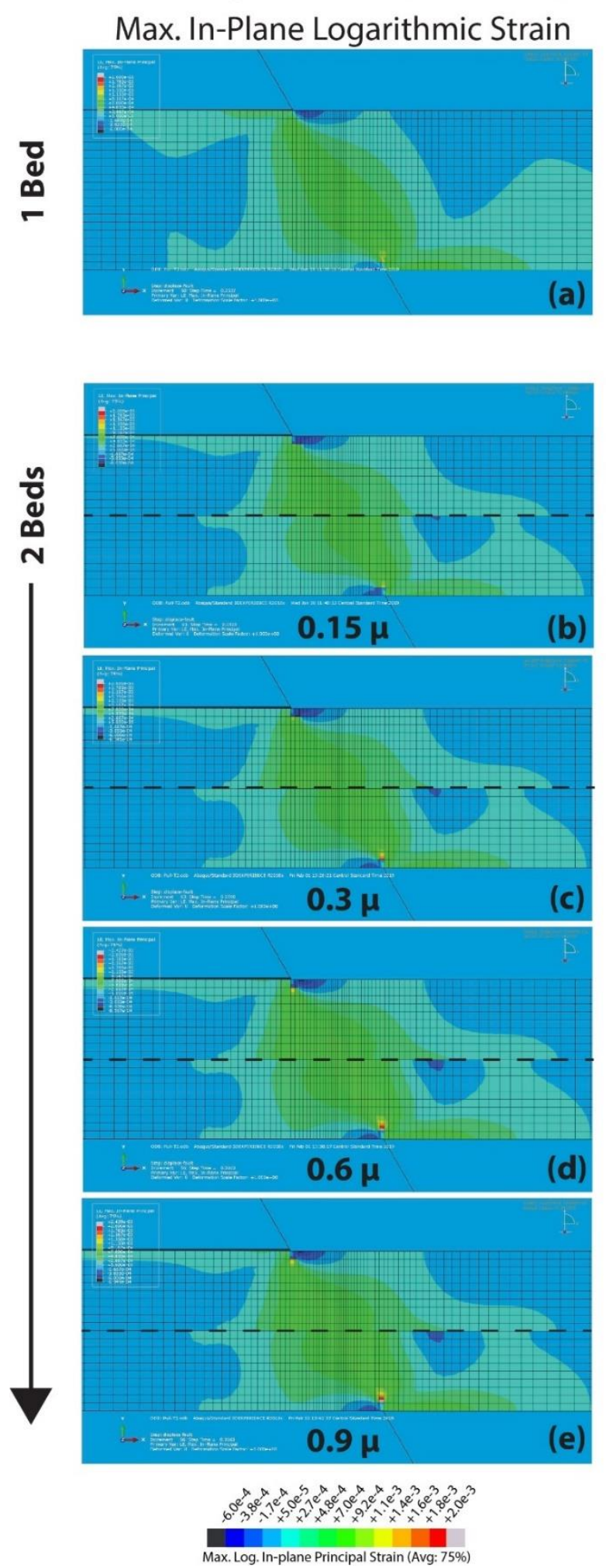

Figure A5. Maximum in-plane principal logarithmic strain distribution at low levels of displacement with one (a) and two beds ( $b-e)$, with increasing friction between beds $(b-e)$. Dashed line indicates bedding plane. Note that strain accumulates in-plane with the fault as well as along contacts. Each model is shown at the displacement causing initial plastic failure; thus, each model is of similar, but not equal, displacement. 


\section{Low Displacement $(<0.040 \mathrm{~m})$}

\section{Max. In-Plane Logarithmic Strain}
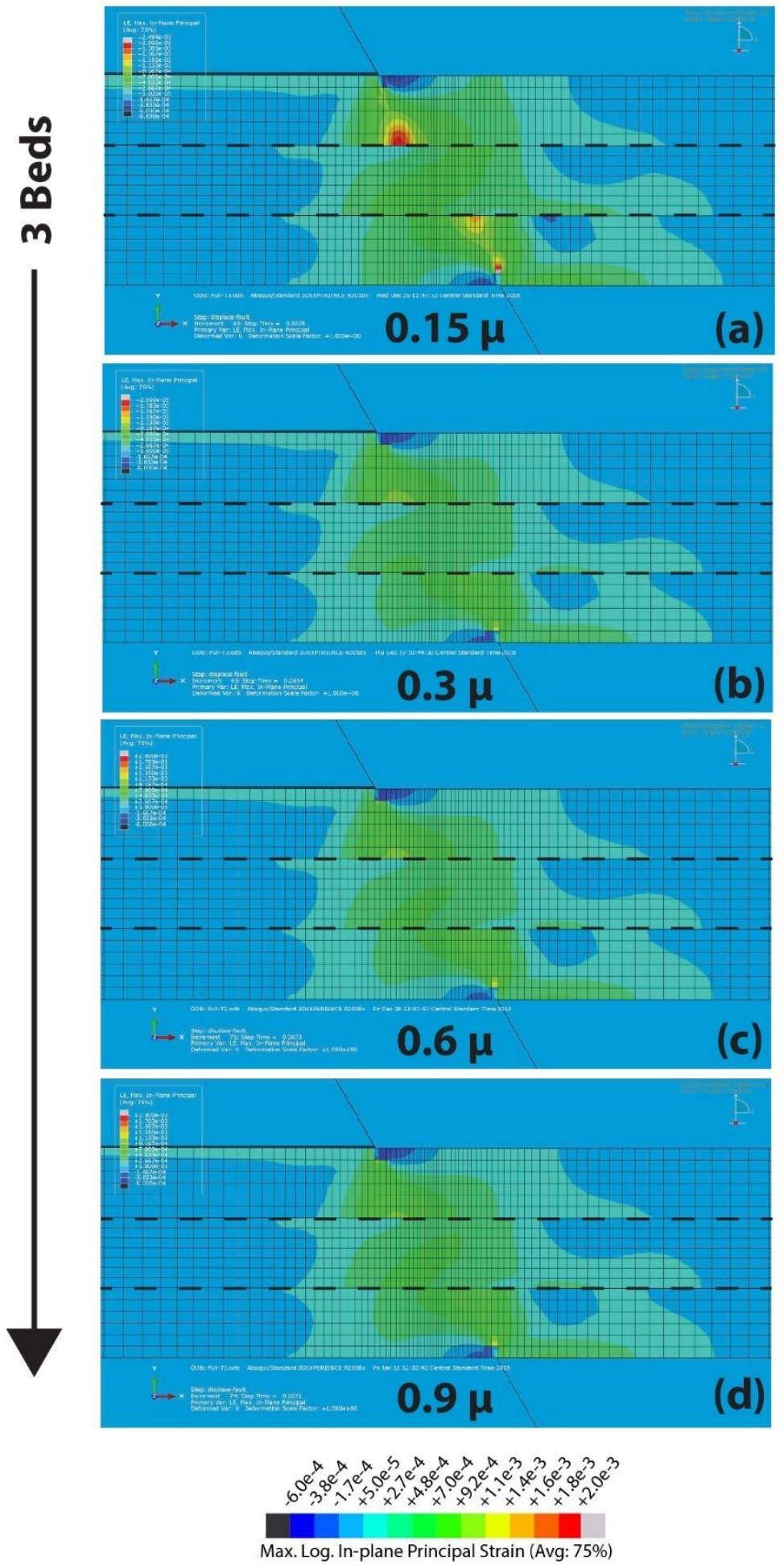

Figure A6. Maximum in-plane principal logarithmic strain distribution at low levels of displacement with three beds, with increasing friction between beds $(a-d)$. Dashed line indicates bedding plane. Note that strain accumulates in-plane with the fault as well as along contacts. Each model is shown at the displacement causing initial plastic failure; thus, each model is of similar, but not equal, displacement. 


\section{Low Displacement $(<0.040 \mathrm{~m})$}

\section{Max. In-Plane Logarithmic Strain}
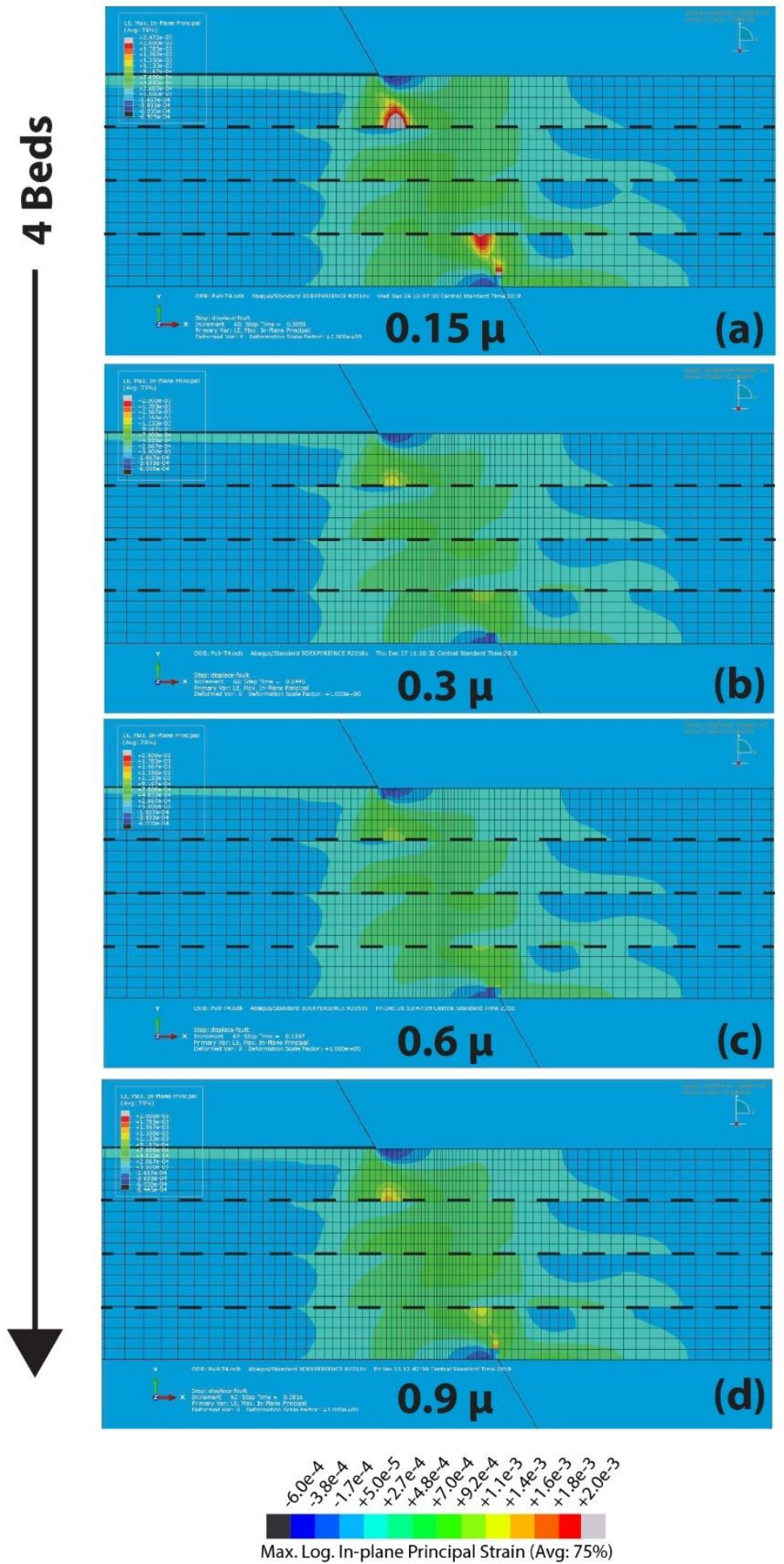

Figure A7. Maximum in-plane principal logarithmic strain distribution at low levels of displacement with four beds, with increasing friction between beds $(a-d)$. Dashed line indicates bedding plane. Note that strain accumulates in-plane with the fault as well as along contacts. Each model is shown at the displacement causing initial plastic failure; thus, each model is of similar, but not equal, displacement. 


\section{Low Displacement $(<0.040 \mathrm{~m})$}

\section{Max. In-Plane Logarithmic Strain}
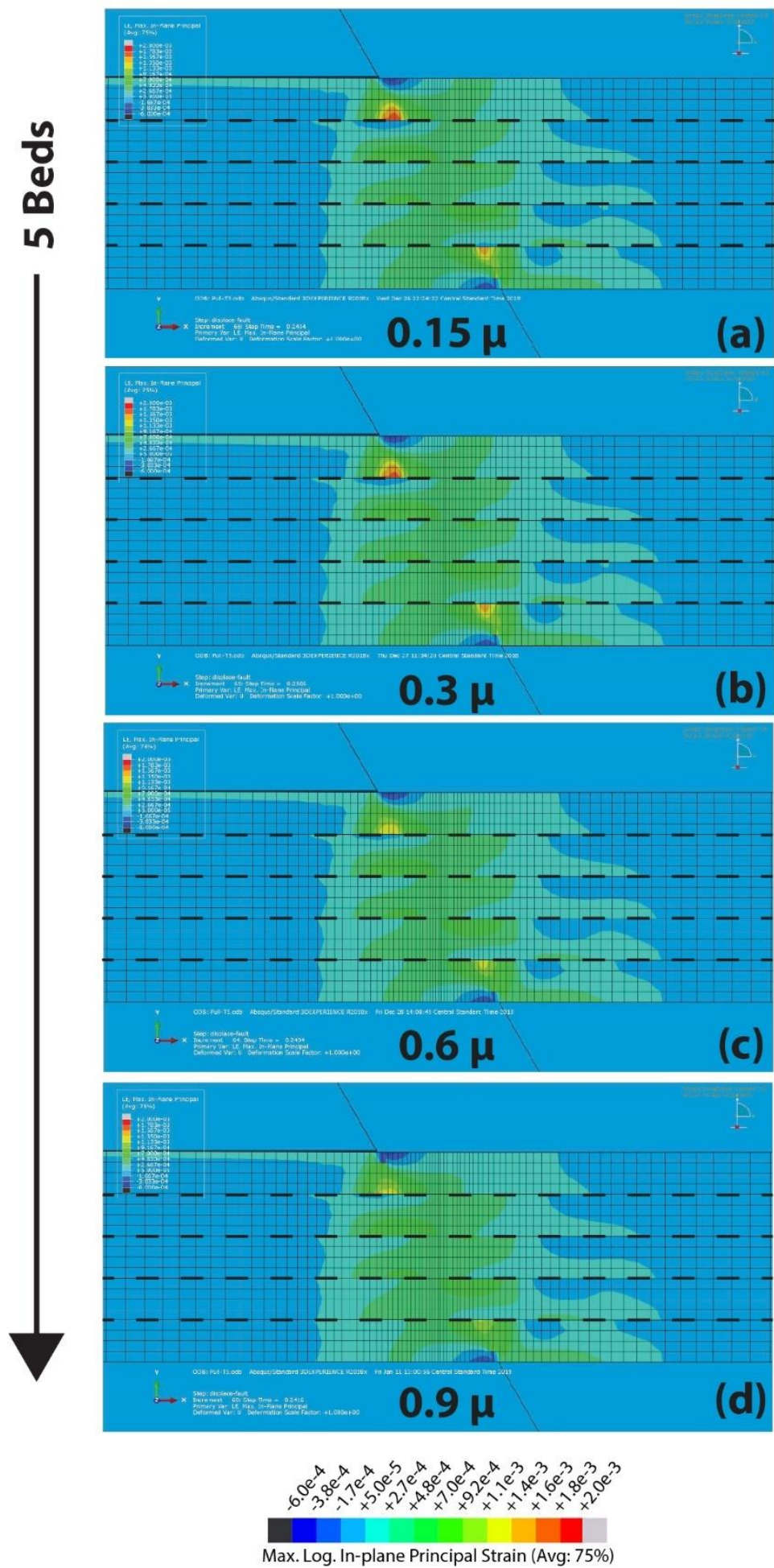

Figure A8. Maximum in-plane principal logarithmic strain distribution at low levels of displacement with five beds, with increasing friction between beds $(a-d)$. Dashed line indicates bedding plane. Note that strain accumulates in-plane with the fault as well as along contacts. Each model is shown at the displacement causing initial plastic failure; thus, each model is of similar, but not equal, displacement. 


\section{REFERENCES CITED}

Bourne, S.J., Brauckmann, F., Rijkels, L., Stephenson, B.J, Weber, A., and Emanuel, J.M., 2000, Predictive modeling of naturally fractured reservoirs using geomechanics and flow simulation in Abu Dhabi International Petroleum Exhibition and Conference, ${ }^{\text {th }}$, Abu Dhabi, U.A.E.

Cardozo, N., Allmendinger, R.W., and Morgan, J.K., 2005, Influence on mechanical stratigraphy and initial stress state on the formation of two fault propagation folds: Journal of Structural Geology, v. 27, p. 1954-1972.

Cook, R.D., 1995, Finite element modeling for stress analysis: John Wiley \& Sons, Inc.

Cooke, M.L., and Pollard, D.D., 1997, Bedding-plane slip in initial stages of fault-related folding: Journal of Structural Geology, v. 19, no. 3-4, p. 567-581.

Cooke M.L., and Underwood, C.A., 2001. Fracture termination and step-over at bedding interfaces due to frictional slip and interface opening, Journal of Structural Geology, 23: $223-238$.

Dassault Systèmes, 2008, Getting started with Abaqus: Interactive edition, version 6.8.

Dassault Systèmes, 2010, Abaqus 6.10 Online Documentation: Dassault Systèmes 2010_04_2715.17.36 37133 .

Dassault Systèmes, 2018, ABAQUS/Standard 3DEXPERIENCE [Computer Software].

Dietrich, J.H., and Decker, R.W., 1975, Finite element modeling of surface deformation associated with volcanism: Journal of Geophysical Research, v. 80, n. 29, p. 4094-4102.

Doff, J., 2015, Geomechanical modeling of a fault-propagation fold [bachelor's thesis]: TUDelft, 2015.

Erickson, S.G., 1996, Influence of mechanical stratigraphy on folding vs. faulting: Journal of Structural Geology, v. 18, p. 443-450.

Hayano, A., and Ishii, E., 2016, Relationship between faults oriented parallel and oblique to bedding in Neogene massive siliceous mudstones at the Horonobe Underground Research Laboratory, Japan: IOP Conf. Ser.: Earth Environ. Sci., v. 44.

Jackson, J., and McKenzie, D., 1983, The geometrical evolution of normal fault systems: Journal of Structural Geology, v. 5, p. 471-482.

Jaeger, J. C., and Cook, N. G. W., 1979, Fundamentals of rock mechanics, 3d ed.: London, Chapman and Hall, p. 593.

Jamison, W.R., 1992, Stress controls on fold thrust style, in McClay, K.R., Ed., Thrust Tectonics: London, Chapman and Hall, p. 155-164. 
Lavier, L.L., Buck, W.R., and Poliakov, A.N.B., 2000, Factors controlling normal fault offset in an ideal brittle layer: Journal of Geophysical Research, v. 105, n. B10, p. 23,431-23,442.

Melosh, H. J., and Williams, C. A. Jr., 1989, Mechanics of graben formation in crustal rocks: A finite element analysis: Journal of Geophysical Research, v. 94, n. 13, p. 961- 13,973.

Menétrey, P., and William, K. J., 1995, Triaxial failure criterion for concrete and its generalization: American Concrete Institute Structural Journal, v. 92, p. 311-318.

Moes, N., Dolbow, J., and Belytschko, T., 1999, A finite element method for crack growth without remeshing: International Journal for Numerical Methods in Engineering, v. 46, p. 131-150.

Ord, A., 1991, Deformation of rock: A pressure-sensitive dilatant material: Pure and Applied Geophysics, v. 137, p. 337-366.

Peacock, D.C.P., 2002, Propagation, interaction and linkage in normal fault systems: EarthScience Reviews, v. 58, p. 121-142.

Rudnicki, J. W., and Rice, J. R., 1975, Conditions for localization of deformation in pressuresensitive dilatant material: Journal of the Mechanics and Physics of Solids, v. 23, p. 371-394.

Sattari, A., and Eaton, D.W., 2015, 3D finite element modeling of fault-slip triggering caused by pore-pressure changes in GeoConvention 2015: New Horizons, Calgary, Canada.

Smart, K.J., Ferrill, D.A., Sims, D.W., Franklin, N.M., Ofoegbu, G.I., Morris, A.P., 2004, Integrated structural analysis and geomechanical modeling: an aid to reservoir exploration and development: Gulf Rocks 2004 - 6th North American Rock Mechanics Symposium: Rock Mechanics Across Borders \& Disciplines. Houston, TX, 5-9 June 2004: ARMA/NARMS Paper 04-470.

Smart, K.J., Ferrill, D.A., and Morris, A.P., 2009, Impact of interlayer slip on fracture prediction from geomechanical models of fault-related folds: American Association of Petroleum Geologists Bulletin 93, 1447-1458.

Smart, K.J., Ferrill, D.A., Morris, A.P., Bichon, B.J., Riha, D.S., and Huyse, L., 2010a, Geomechanical modeling of an extensional fault-propagation fold: Big Brushy Canyon monocline, Sierra Del Carmen, Texas: American Association of Petroleum Geologists Bulletin 94, 221-240.

Smart, K.J., Ferrill, D.A., Morris, A.P., and McGinnis, R.N., 2010b, Geomechanical modeling of a reservoir-scale fault-related fold: the Bargy anticline, France: 44th U.S. Rock Mechanics Symposium, ARMA Paper 10-201.

Smart, K.J., Ferrill, D.A., Morris, A.P., and McGinnis, R.N., 2012, Geomechanical modeling of stress and strain evolution during contractional fault-related folding: Tectonophysics, v. 576-577, p. 171-196. 
Smart, K.J, 2018, personal communication.

Smart, K.J, 2019, personal communication.

Vermeer, P. A., and DeBorst, R., 1984, Non-associated plasticity for soils, concrete and rock: Heron, v. 29, p. 1-64.

Xing, H.L., Makinouchi, A., and Mora, P., 2007, Finite element modeling of interacting fault systems: Physics of the Earth and Planetary Interiors, v. 163, p. 106-121.

Young-Seog, K., Peacock, D. C. P., and Sanderson, D. J., 2004, Fault damage zones: Journal of Structural Geology, v. 26, p. 503-517.

Zienkiewicz, O. C., and Mroz, Z., 1984, Generalized plasticity formulation and applications to geomechanics, in C. S. Desai and R. H. Gallagher, eds., Mechanics of engineered materials: Chichester, JohnWiley and Sons, Inc., p. 655-679. 